\title{
Evaluation of coastal inundation hazard for present and future climates
}

\author{
Andrew J. Condon • Y. Peter Sheng
}

Received: 31 August 2011/Accepted: 26 September 2011/Published online: 12 October 2011

(C) The Author(s) 2011. This article is published with open access at Springerlink.com

\begin{abstract}
Coastal inundation from hurricane storm surges causes catastrophic damage to lives and property, as evidenced by recent hurricanes including Katrina and Wilma in 2005 and Ike in 2008. Changes in hurricane activity and sea level due to a warming climate, together with growing coastal population, are expected to increase the potential for loss of property and lives. Current inundation hazard maps: Base Flood Elevation maps and Maximum of Maximums are computationally expensive to create in order to fully represent the hurricane climatology, and do not account for climate change. This paper evaluates the coastal inundation hazard in Southwest Florida for present and future climates, using a high resolution storm surge modeling system, CH3D-SSMS, and an optimal storm ensemble with multivariate interpolation, while accounting for climate change. Storm surges associated with the optimal storms are simulated with CH3D-SSMS and the results are used to obtain the response to any storm via interpolation, allowing accurate representation of the hurricane climatology and efficient generation of hazard maps. Incorporating the impact of anticipated climate change on hurricane and sea level, the inundation maps for future climate scenarios are made and affected people and property estimated. The future climate scenarios produce little change to coastal inundation, due likely to the reduction in hurricane frequency, except when extreme sea level rise is included. Calculated coastal inundation due to sea level rise without using a coastal surge model is also determined and shown to significantly overestimate the inundation due to neglect of land dissipation.
\end{abstract}

Keywords Storm surge modeling · Climate change · Inundation maps · Joint probability method $\cdot$ Hurricanes $\cdot$ Sea level rise

\footnotetext{
A. J. Condon · Y. Peter Sheng ( $₫)$

Civil and Coastal Engineering Department, University of Florida, 365 Weil Hall,

Gainesville, FL 32611-6580, USA

e-mail: pete@coastal.ufl.edu
} 


\section{Introduction}

Coastal inundation from hurricane-induced storm surge and waves can wreak havoc in coastal regions as has been witnessed during recent Hurricanes Ivan, Katrina, Wilma, Ike, and Rita among others. Over the past 15 years, North Atlantic hurricane activity has entered a more active cycle, and landfalls along the U.S. coast have become more common (Goldenberg et al. 2001; Knutson et al. 2007). Coupled with this, coastal construction and population growth continue to increase making the inundation hazard even greater, resulting in 14 of the 30 costliest storms (from 1900 to 2006, in normalized to 2006 dollars) occurring since 1990 (Blake et al. 2007). Hurricane Katrina alone resulted in an estimated $\$ 81$ billion worth of damage and more than 1,500 deaths (Blake et al. 2007). With the increased potential for such catastrophic damage, the hazard of inundation from hurricanes needs to be quantified in an efficient manner with sufficient spatial resolution to provide useful information to coastal planners and decision makers.

The present day coastal inundation hazard analysis takes into account the natural variability in hurricane frequency, size, intensity, and track. The hazard analysis is described in detail in recent reports by Federal Emergency Management Agency (FEMA 2008), Interagency Performance Evaluation Taskforce (IPET 2009), and the National Academies Committee on FEMA Flood Mapping Accuracy (NRC 2009). The analysis requires the use of a robust storm surge modeling system (which includes processes such as tides, waves, and on-land structures) to simulate the response of coastal zone to a statistically generated ensemble of hurricanes using the joint probability method (JPM). This method generally requires a large number (thousands or larger) of hurricanes in order to adequately represent the past hurricane climatology in a given coastal region. Running this large number of hurricanes with a robust storm surge modeling system requires excessive computational effort. To save computational cost, existing inundation maps are generally created with a small number of $(\sim 100)$ storms which may not adequately represent the past storm statistics. Effort to more adequately represent the past storm statistics has begun in recent years with the development of the JPM-OS method (Resio 2007; Agbley 2009; Toro et al. 2010a, b; Niedoroda et al. 2010) and applications to Louisiana and Mississippi coasts. These methods, which are somewhat different in the multi-dimensional quadrature interpolation algorithm, made the generation of probabilistic inundation maps much more efficient.

Moreover, the present day coastal inundation hazard analysis does not include any effect of climate change and anticipated sea level rise (Lin et al. 2010). Evidence suggests that a warming planet may lead to more intense storms (Knutson et al. 2010), although the frequency of the landfalling hurricanes is expected to be less (Wang and Lee 2008). Wang and Lee (2008) concluded that model projections of ocean warming patterns under future global warming scenarios may be crucial in predicting future Atlantic hurricane activity. Additionally, they believe that anthropogenic global warming has a pervasive influence on both oceanic and atmospheric temperatures and circulation as well as water vapor, all of which affect tropical cyclones in complex and not yet fully understood ways. Compounding the issue is the effect of sea level rise (SLR) which could produce a global mean increase in water level of up to $190 \mathrm{~cm}$ over the next century when considering the contribution from land ice (Grinsted et al. 2009; Vermeer and Rahmstorf 2009; Rahmstorf 2010). Combining the continual migration of people to the coast with potential climate change impacts, it is likely that future hurricanes could lead to more costly and deadly damages to the coastal zone. To properly plan for the future, potential changes in coastal inundation hazard due to climate change need to be accounted for. Although a few studies 
(Frazier et al. 2010; Kleinosky et al. 2007; Wu et al. 2002) have examined the impact of SLR on coastal inundation, these studies did not use any storm surge and inundation modeling system, nor did they include the effect of climate change on hurricane intensity and frequency; hence, the results are questionable. Mousavi et al. (2011) and Frey et al. (2010) both accounted for changes in hurricane intensity and SLR to determine the impact of climate change on inundation in Corpus Christi, TX, using a storm surge modeling system. However, these studies neglect the expected decrease in hurricane frequency and examine individual historical storms, rather than generating probabilistic hazard analysis (BFE) maps and worst-case scenario maps (MOM). Feyen et al. (2006), on the other hand, used a storm surge model to study the effect of SLR alone on coastal inundation. Ali (1996, 1999) also incorporated SLR into inundation projections for Bangladesh; however, his results were obtained with a stationary, uniform wind, not the dynamic winds expected in a hurricane. Danard et al. (2003) among others investigated the effects of SLR on storm surge for non-tropical storms, but did not include any changes in storm intensity or frequency. This study will incorporate changes in hurricane intensity and frequency as well as SLR to develop probabilistic hazard maps for Southwest FL. In addition, worst-case composite maps (MOMs) will be developed for future SLR scenarios.

This paper intends to answer the following questions: How will the coastal hazard maps for future climate differ from that for the present climate, and why? How does a coastal hazard map produced in this study differ from that produced without using a coastal storm surge model? What will a coastal inundation hazard map look like? What is the hazard of coastal inundation induced damage on coastal property and population?

To accurately and efficiently quantify the coastal inundation hazard in any coastal zone, we believe it is necessary to (1) use a robust integrated storm surge and inundation modeling system to account for coastal dynamics and atmospheric-ocean-land interactions; (2) use an efficient and portable JPM-OS method to statistically generate a hurricane ensemble with relatively small number ( hundreds) of hurricanes to accurately represent the hurricane statistics; and (3) incorporate the potential impact of climate change on hurricane intensity and frequency as well as sea level rise.

This paper evaluates the present day inundation hazard to the Southwest Florida coast using the integrated storm surge and inundation modeling system $\mathrm{CH} 3 \mathrm{D}$ (Curvilinear-grid Hydrodynamics in 3D)-SSMS (Sheng et al. 2010a, b) and a relatively small ( $<200$ storms) but optimal hurricane ensemble generated by an efficient and portable JPM-OS Method based on Smolyak's (1963) multi-dimensional quadrature interpolation algorithm. Our method is similar to that used by Resio (2007) and Toro et al. (2010a, b), but more similar to Agbley (2009) which also used the Smolyak's algorithm. The effect of climate change on hurricane intensity and frequency is incorporated in the JPM-OS method. Three sea level rise scenarios for the year 2100 are created and simulated to develop likely coastal inundation hazard. This study will also calculate the coastal inundation due to SLR, with and without using a coastal storm surge model, and compare the difference in coastal inundation calculated by these two different methods.

\subsection{Study area}

The state of Florida has experienced tremendous growth over the past few decades. Since 1990, the population has increased by over 5.8 million people according to the United States Census (http://2010.census.gov). The Southwest Florida region has seen an explosive population growth, particularly since the start of this century. It was estimated that the population for the region would increase by $47 \%$ from 2000 to 2010 (University of Florida 
2009) and an estimated 138\% over the 2000 population by 2030 (University of Florida 2005). With such a large projected increase in population, the region is ideal for the evaluation of present and future coastal inundation hazard. This region was selected as the main focus of the NOAA/IOOS (National Atmospheric and Oceanic Administration/ Integrated Ocean Observing System) Regional Storm Surge and Inundation Model Testbed developed by Sheng et al. (2011).

The study area stretches from just south of Tampa Bay to Cape Sable in the Ten Thousand Island region and includes parts of Manatee, Sarasota, Charlotte, Lee, Collier, and Monroe counties (Fig. 1a). In addition to being an area with explosive population growth in recent decades, there is a concentration of wealth along the coast that is vulnerable to inundation (Fig. 1b). The region has been affected by a number of tropical systems over the past 70 years including major hurricanes Donna (1960), Charley (2004), and Wilma (2005) (see Table 1; Fig. 2). Data of U.S. landfalling hurricanes, which account for one-third of the North Atlantic hurricanes, have been used extensively for analyzing the potential influence of climate on hurricanes (Emanuel 2005; Landsea 2005).

As shown in Fig. 1a, a numerical model grid of this region has been constructed for use with the CH3D (Sheng 1987, 1990)—Storm Surge Modeling System (CH3D-SSMS) (Sheng et al. 2006, 2010a, b; Sheng and Paramygin 2010). The model domain is currently being used in the NOAA/IOOS Regional Storm Surge and Coastal Inundation Model Testbed which is comparing 5 different storm surge and inundation models: ADCIRC (ADvanced CIRCulation) (Luettich et al. 1992), CH3D-SSMS, POM (Princeton Ocean Model) (Peng et al. 2004; Oey et al. 2006), FVCOM (Rego and Li 2009; Weisberg and Zheng 2008), and SLOSH (Sea, Lake, and Overland Surges from Hurricanes) (Jelesnianski et al. 1992) in terms of historical hurricane simulations and coastal inundation maps including Maximum of Maximums (MOMs) and Base Flood Elevation (BFEs) maps (Sheng et al. 2011).

\subsection{Current storm surge hazard products: inundation maps}

Currently, the hazard from storm surge and coastal inundation is described by two different products, i.e., inundation maps: the Maximum of Maximum (MOM) and the Base Flood Elevation (BFE) maps. The MOM (National Hurricane Center 2010a), which is produced based on SLOSH simulations of numerous hurricanes, represents the worst-case scenario for a given region for a given Saffir-Simpson Hurricane Scale (SSHS) (National Hurricane Center 2010b) storm category. In Florida, the NOAA/NHC (National Hurricane Center) SLOSH group produces the model simulations, and the Florida Regional Planning Councils use the SLOSH results to produce MOMs of five hurricane categories. The BFE determines the inundation hazard with an associated (typically 1\%) annual chance of occurrence or a particular return period (typically 100 years) and is the main component of FEMA's Flood Insurance Rate Maps (FIRMs) (FEMA 2007; NRC 2009). Generation of these products typically requires the numerical simulation of thousands or more of hypothetical hurricanes which represent the past hurricane statistics, i.e., historical hurricane climatology, for the region. The MOM is the maximum inundation obtained from an ensemble of thousands of hypothetical storms for a specific SSHS category with various tracks (angle, landfall location, and forward speed) and storm sizes (radius of maximum winds). FEMA creates BFE maps by use of the joint probability method (JPM) (FEMA 2008) in which the historical climatology of a region is described probabilistically and is combined with the simulated surge response covering the entire parameter space to determine the inundation for a set annual probability of occurrence $(1 \%)$ or return period 

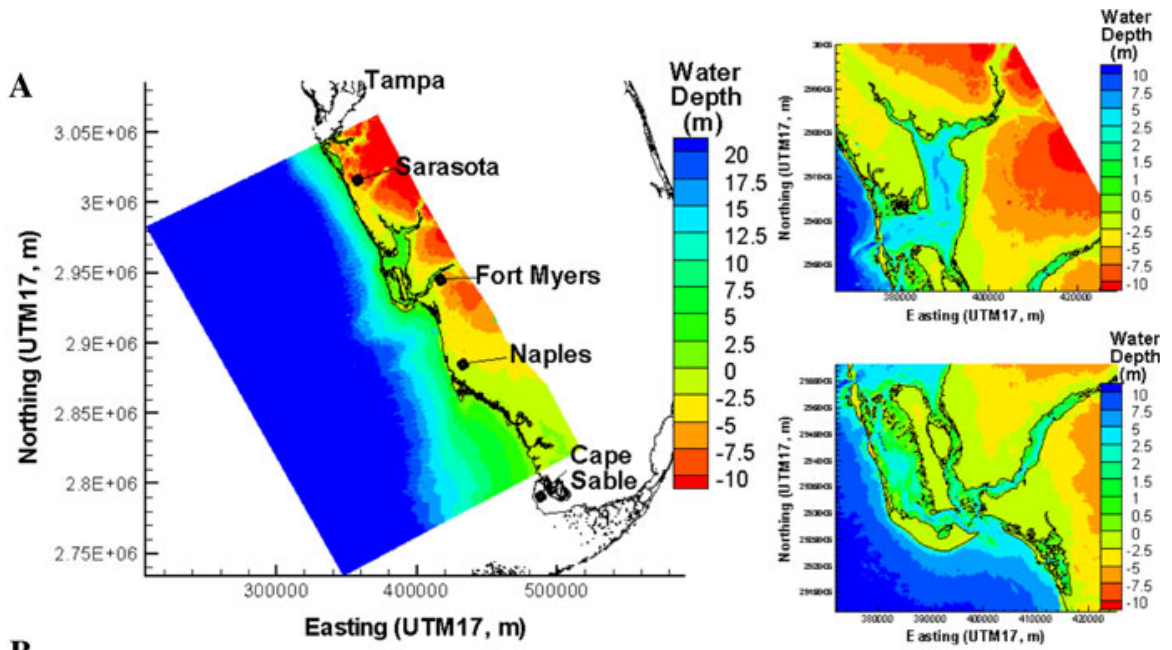

B

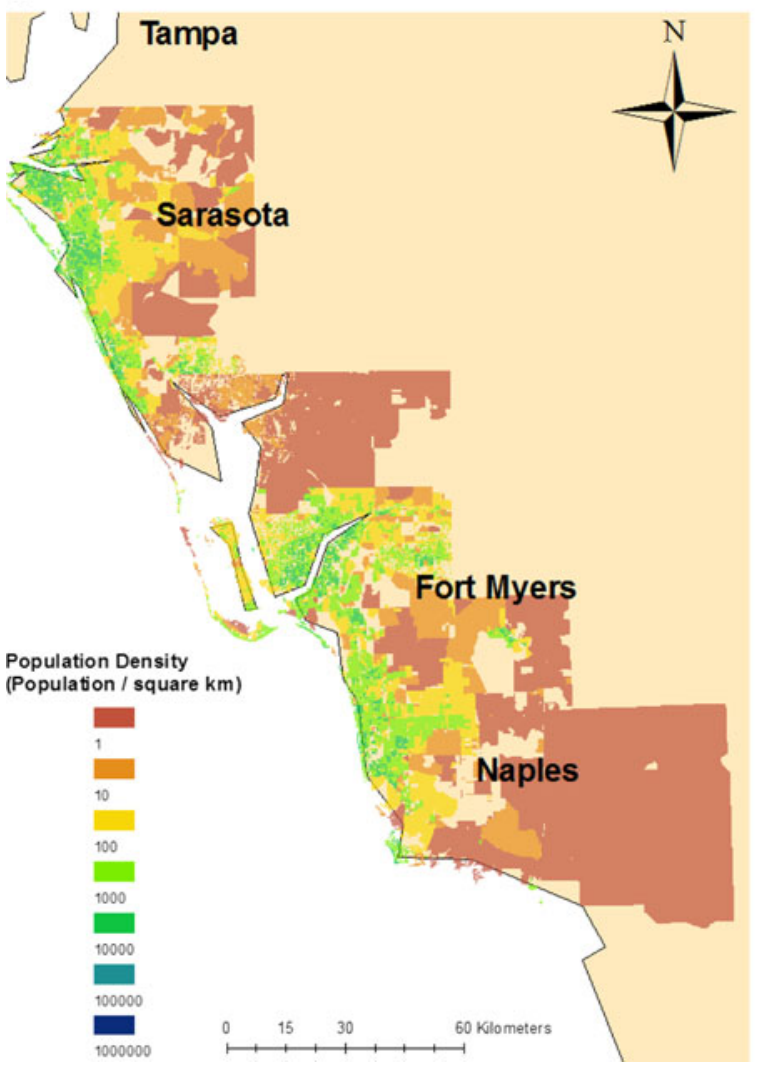

Fig. 1 a CH3D-SSMS model domain for SW FL with focus on Fort Myers and Sanibel Island. b Population density map for the study domain (Population/ $\mathrm{km}^{2}$ ): Northern boundary is Tampa Bay and southern boundary is Cape Sable 
Table 1 Historical hurricane parameters

\begin{tabular}{|c|c|c|c|c|}
\hline Historical storm (year) & $\begin{array}{l}\text { Central pressure } \\
\text { deficit }(\mathrm{hPa})\end{array}$ & $\begin{array}{l}\text { Radius to maximum } \\
\text { winds }(\mathrm{km})\end{array}$ & $\begin{array}{l}\text { Forward speed } \\
(\mathrm{m} / \mathrm{s})\end{array}$ & $\begin{array}{l}\text { Storm heading } \\
\left({ }^{\circ} \mathrm{N}\right)\end{array}$ \\
\hline Not named (1944) & 45 & 63 & 8.0 & 10 \\
\hline Not named (1945) & 37 & - & 5.8 & 62 \\
\hline Not named (1946) & 27 & 46 & 8.5 & 13 \\
\hline Not named (1947) & 22 & - & 4.0 & 12 \\
\hline Not named2 (1947) & 29 & 24 & 6.7 & 39 \\
\hline Not named (1948) & 52 & 13 & 3.6 & 24 \\
\hline Not named2 (1948) & 38 & 24 & 7.6 & 42 \\
\hline Easy (1950) & 55 & 28 & 2.2 & 24 \\
\hline Love (1950) & 23 & - & 8.0 & 46 \\
\hline How (1951) & 20 & - & 7.2 & 81 \\
\hline Not named (1953) & 28 & - & 8.9 & 51 \\
\hline Hazel (1953) & 23 & - & 8.9 & 46 \\
\hline Judith (1959) & 14 & - & 5.8 & 45 \\
\hline Donna (1960) & 75 & 44 & 4.0 & 338 \\
\hline Isbell (1964) & 45 & 56 & 7.2 & 36 \\
\hline Abby (1968) & 20 & - & 4.0 & 27 \\
\hline Gladys (1968) & 36 & 31 & 3.6 & 47 \\
\hline Floyd (1987) & 20 & - & 7.6 & 61 \\
\hline Keith (1988) & 18 & 135 & 7.6 & 65 \\
\hline Marco (1990) & 14 & 19 & 4.0 & 354 \\
\hline Gordon (1994) & 18 & 148 & 4.0 & 27 \\
\hline Mitch (1998) & 23 & 278 & 8.9 & 62 \\
\hline Irene (1999) & 27 & 74 & 4.5 & 33 \\
\hline Gordon (2000) & 24 & 46 & 4.9 & 21 \\
\hline Gabrielle (2001) & 30 & 46 & 8.0 & 34 \\
\hline Charley (2004) & 66 & 19 & 8.9 & 15 \\
\hline Wilma (2005) & 60 & 56 & 7.6 & 47 \\
\hline Fay (2008) & 19 & 37 & 2.7 & 10 \\
\hline
\end{tabular}

(100 years). MOM, however, does not contain any probabilistic information such as annual chance of occurrence or return period of any inundation elevation. Combining these hazard analyses with demographic and property value information can portray the risk to a certain area.

Both the MOM and BFE, which are intended to relay the potential of coastal inundation, have been used widely by emergency managers, coastal planners, and the public, despite the uncertainties associated with the inundation levels shown on these maps (NRC 2009). When a larger storm ensemble is used in the production of inundation maps, there is less uncertainty associated with the representation of the storm climatology. However, the cost for running a larger ensemble of storms can become excessive. Currently, a single simulation using a state-of-the-art storm surge modeling system can take hours to days on a single computer processor, necessitating a cluster with hundreds or thousands of processors.

In the past, to reduce the computational cost, model physics and resolution are often compromised and the number of simulations is arbitrarily reduced which leads to 


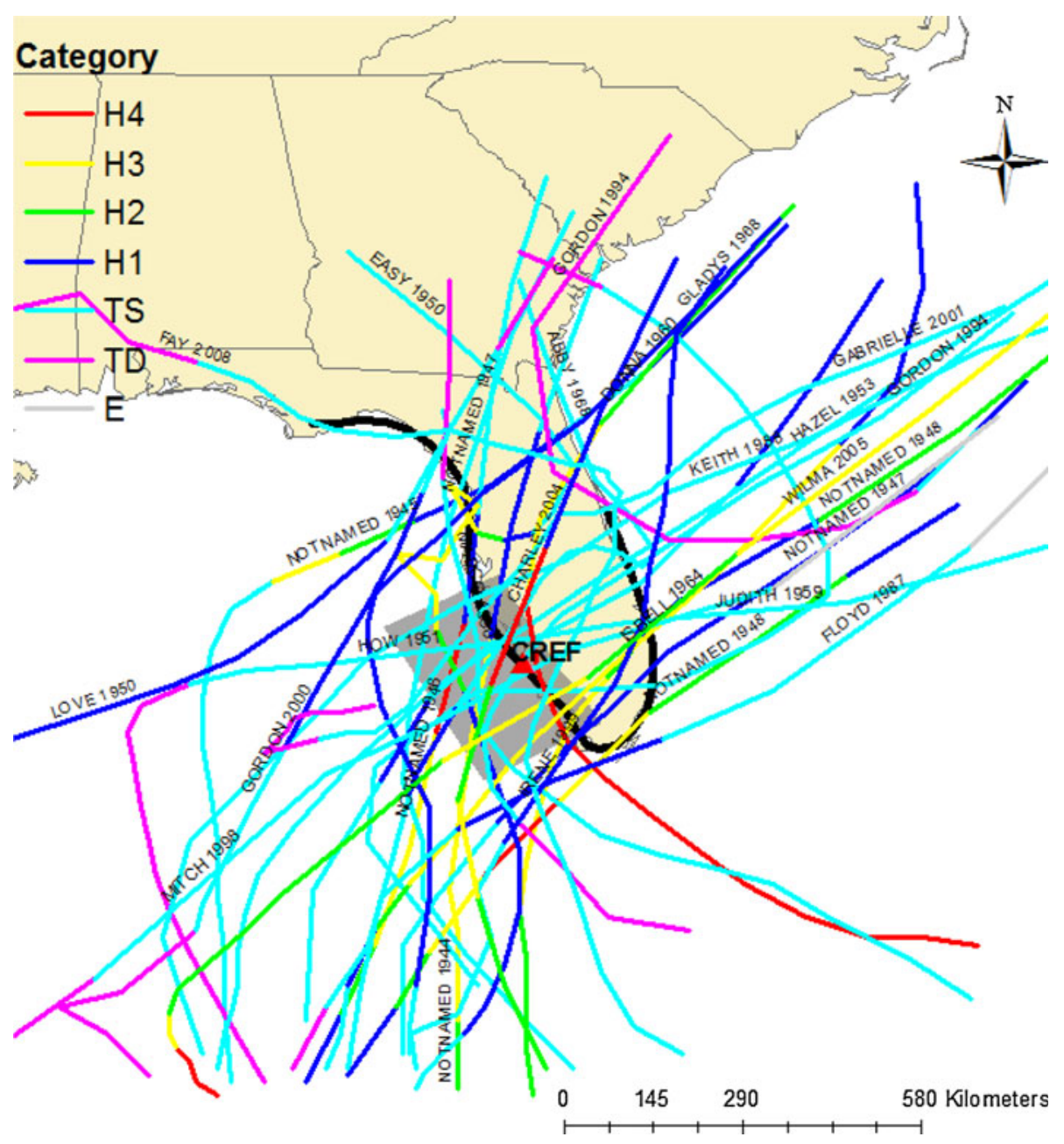

Fig. 2 Study area featuring CH3D-SSMS model domain and tracks of tropical storms influencing the area since 1940. Central reference point (CREF) defined as Fort Myers Beach, FL

inaccurate representation of the storm climatology. More recently, new robust methods (Toro et al. 2010a, b; Resio 2007; Niedoroda et al. 2010; Agbley 2009; Lin et al. 2010) have been developed to create a smaller ensemble of storms for producing BFEs. The JPM optimal sampling (JPM-OS) methods have led to a reduction in the number of storms needed for simulations by orders of magnitude, from tens of thousands to only hundreds of storms. With a smaller storm ensemble size, more advanced numerical modeling systems with better physics and finer model resolution can be used in the storm surge simulations. This paper uses a JPM-OS method similar to those used by Toro et al. (2010a, b) and Resio (2007), Irish et al. (2009), which used a different quadrature interpolation algorithm. Our method uses Smolyak's (1963) quadrature interpolation algorithm, which was used in Agbley (2009) as well, to develop an optimal storm ensemble for both the BFE and MOM development. Our method differs slightly from Agbley (2009) which uses a simple wind model to interface with the dimension adaptive sparse grid scheme for selection of the 
optimal storms, while we take into account important storm surge components such as landfall location and angle of approach to the coast. The method employed here couples the storm surge model SLOSH with the dimension adaptive scheme so that all five JPM variables are represented in the selection of the optimal storms. For simplicity, the complete details of our method can be found elsewhere in Condon and Sheng (2011). The optimal inundation maps will be combined with economic and population data in Southwest Florida to give a quantitative measure of the inundation risk. Additionally, the projections of future climate scenarios will be used to determine the coastal inundation hazard expected in the year 2100 .

\section{Optimal storm generation and storm surge modeling}

\subsection{Optimal storm ensemble generation}

Following the destruction caused by Hurricane Katrina, there is a consensus in the U.S. that it is necessary to more accurately estimate storm surge and inundation hazards in coastal regions (see, e.g., IPET 2009; NRC 2009). Several recent studies (Resio 2007; Toro et al. 2010a, b; Niedoroda et al. 2010) have been conducted to better represent the storm surge and coastal inundation hazards in terms of the expected return period (or annual chance of occurrence) of such events. The method of choice by FEMA for obtaining inundation frequencies is the joint probability method (JPM) (Myers 1970), which traditionally uses the probabilistic descriptions of the historical storm rate and storm characteristics to define a set (or ensemble) of synthetic storms. The synthetic storm set/ensemble is then used by a numerical storm surge model to calculate the coastal flood elevations that would be generated by each of those storms. The probabilistic descriptions are combined with the calculated inundation to generate the annual probability of exceeding any desired storm stage. The approach is widely accepted in the emergency management community and officially adopted by FEMA (Divoky and Resio 2007; Agbley and Basco 2008).

The downside to the traditional JPM is that accurate representation of historical storm climatology requires tens of thousands of numerical model simulations. Hurricanes are parameterized by five variables: the central pressure deficit $\Delta \mathrm{P}$, the storm size $\mathrm{R}_{\max }$, the translational speed $\mathrm{V}_{\mathrm{f}}$, the storm heading $\theta$, and the landfall location $\mathrm{X}_{\text {land }}$-based on the local climatology. A detailed study of the local climatology is usually conducted to develop a discrete probability distribution function (pdf) of each variable. Finer discretization of the pdfs will yield more accurate representation of the climatology, but it would often require tens of thousands of storm surge model simulations. This could translate into hundreds or thousands of computational hours using one of the state-of-the-art storm surge modeling systems mentioned above.

Following Katrina, optimization schemes for the JPM (Toro et al. 2010a, b; Niedoroda et al. 2010; Resio 2007; Agbley 2009) were developed to enable the production of accurate inundation maps with only hundreds of model simulations instead of tens of thousands of model simulations. These optimized schemes have allowed the production of accurate maps with dramatically reduced computational cost over running the same model with the traditional JPM scheme.

For this study, we use a method based on Smolyak (1963). As pointed out by Toro et al. (2010a), this method reduces the number of parameter combinations needed in multidimensional quadratures, leading to a drastically reduced number of synthetic storm combinations. This method was described by Agbley (2009) and is modified by us to make 
Fig. 3 Comparison between 100-year flood map (BFE) created using the traditional JPM (46,800 storm simulations) and that created using the optimal method of Condon and Sheng (2011) (197 storm simulations, red) and that created using a random ensemble (197 storm simulations, blue)

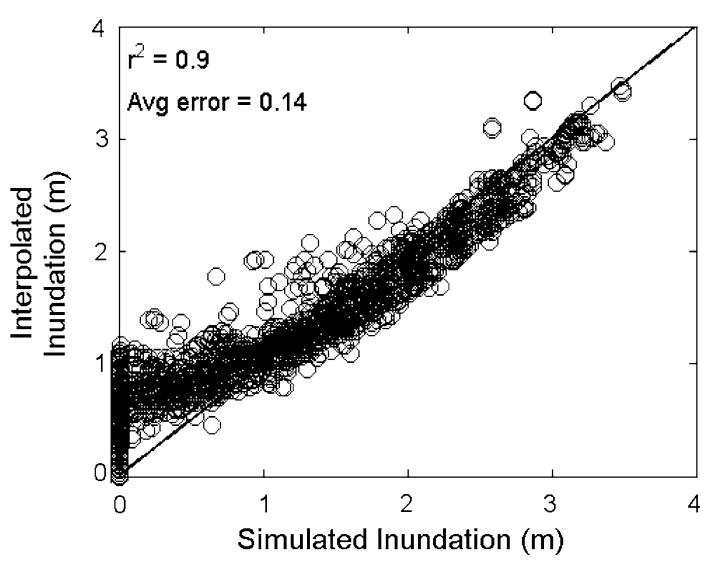

it more transportable and accurate. This method can be fully automated and readily applied to other basins with minimal set up. Our method develops an optimal set of $(\sim 100)$ storms, based on the algorithm of Smolyak (1963). From this optimal storm database, the surge response for any storm can be obtained using multivariate adaptive regression splines (Friedman 1991), similar to Resio (2007) and Niedoroda et al. (2010). Our storm generation algorithm modifies Smolyak's algorithm by incorporating dimension adaptivity (Gerstner and Griebel 2003) using the surge response generated with the highly efficient SLOSH (Jelesnianski et al. 1992) model to develop the optimal storms. Condon and Sheng (2011) used the optimal storm ensemble generation method with the SLOSH model to show that the resulting inundation map is almost identical to that generated using 46,800 storms which fully represent the storm climatology. Figure 3 shows a comparison between the results of the BFE with $1 \%$ chance of occurrence using a traditional JPM $(46,800$ simulations) and an optimal (197 simulations) ensemble. The optimal storm ensemble creates a BFE map with an average error within $15 \mathrm{~cm}$ of that obtained using the traditional JPM but at a fraction of the cost.

\subsection{CH3D-SSMS: CH3D-based storm surge modeling system}

In this study, the high resolution storm simulations are performed using CH3D-SSMS. CH3D is a hydrodynamic model originally developed by Sheng $(1987,1990)$ and has been significantly enhanced (e.g., Sheng and Kim 2009; Sheng et al. 2010a). The model can simulate 2-D and 3-D barotropic and baroclinic circulation driven by tide, wind, wave, and density gradients. The model uses a boundary-fitted non-orthogonal curvilinear grid in the horizontal directions and terrain-following sigma grid in the vertical direction to allow accurate representation of the complex coastal and estuarine shorelines where forecasting of storm surge, waves, and inundation is needed. Based on the finite volume method, $\mathrm{CH} 3 \mathrm{D}$ is strictly conservative for momentum, water mass, as well as for temperature and salinity. $\mathrm{CH} 3 \mathrm{D}$ uses a robust second-order closure model for calculating vertical turbulent mixing (Sheng and Villaret 1989). In the horizontal direction, Smagorinksy-type turbulent diffusion coefficients are used. CH3D is used for simulating and forecasting storm surge and circulation in many coastal regions throughout Florida and the U.S.

CH3D, which supports flooding and drying, has been dynamically coupled to a wave model SWAN (Booij et al. 1999; Ris et al. 1999; SWAN Team 2009), using the same 
curvilinear grid, to produce CH3D-SSMS, an integrated Storm Surge Modeling System (Sheng et al. 2006, 2010a, b). To provide open boundary conditions of water level along the coastal model CH3D domain, CH3D-SSMS can use the results of one of several basinscale hydrodynamic models, including ADCIRC (Luettich et al. 1992), HYCOM (Halliwell et al. 1998; Bleck 2002), and NCOM (Ko et al. 2003, 2008). In this study, ADCIRC is used. To provide open boundary condition for SWAN, CH3D-SSMS uses the output of a large-scale wave model such as WaveWatch-III (Tolman 1999, 2002). CH3DSSMS has been used extensively to simulate storm surge and inundation due to various tropical storms including Hurricane Isabel (Sheng et al. 2010a), Charley (Sheng et al. 2006; Davis et al. 2008, 2010), Ivan (Sheng et al. 2010b), and Wilma (Paramygin and Sheng 2011). Sheng and Paramygin (2010) combined the baroclinic circulation element of CH3D with CH3D-SSMS to forecast the storm surge, inundation, and 3D baroclinic circulation in northeast Florida during Tropical Storm Fay.

For this study, CH3D-SSMS uses the local CH3D model dynamically coupled with local SWAN wave model. Offshore conditions are provided to $\mathrm{CH} 3 \mathrm{D}$ by a coarse grid ADCIRC simulation, and offshore wave boundary conditions are provided to the local SWAN model by a coarse grid larger scale SWAN domain. Little difference (less than $0.01 \%$ ) was found in the final results between using SWAN or WWIII in the offshore for the wave boundary conditions, so SWAN was used to ease nesting with the local-scale domain. CH3D-SSMS uses wind fields developed by an analytic model based on Holland (1980). The winds are developed as straight line tracks of constant intensity until landfall. For this study, the storm intensity is dissipated following Vickery (2005) post landfall. To save computational cost, this study runs the $\mathrm{CH} 3 \mathrm{D}$ model in $2 \mathrm{D}$ (vertically averaged) mode. A spatially varying Manning's n coefficient is developed based on land use data obtained from United States Geological Survey (USGS 2010b) with an offshore value of 0.02 (dimensionless). The coastal model domain features a minimum horizontal resolution of approximately $20 \mathrm{~m}$ in the coastal zone and an overall average grid size of $\sim 100 \mathrm{~m}$ with a maximum of $\sim 700 \mathrm{~m}$ offshore. The most up-to-date LIDAR from NOAA Coastal Services Center (NOAA CSC 2010), topography from United States Geological Survey (USGS 2010a), and bathymetry data from NOAA National Geophysical Data Center (NOAA NGDC 2010) have been incorporated into the domain shown in Fig. 1.

\section{Probabilistic description of present hurricane climatology}

To determine the coastal inundation hazard to the region, a detailed study of the local hurricane climatology is needed. This was presented in Condon and Sheng (2011) and is summarized here.

\subsection{Dataset and period of record}

Data from 1940 to the present are considered to be more reliable than earlier data since it incorporates aircraft reconnaissance and the satellite era (Resio 2007). To represent the local hurricane climatology, this study uses hurricane data during the 70-year period from 1940 to 2009 obtained from the International Best Track Archive for Climate Stewardship (IBTrACS) dataset (Knapp et al. 2010). This dataset is used along with Ho et al. (1987) to obtain the parameters of interest: $\Delta P, R_{\max }, V_{\mathrm{f}}, \theta$, and $X_{\text {land }}$ for land-falling cyclones along the simplified coastline shown in Fig. 2. 
A total of 28 land-falling storms were determined to influence the southwest coast of Florida during this 70-year period, based on an optimal kernel width calculated by the method of Chouinard and Liu (1997). The tracks are depicted in Fig. 2, and the parameters at landfall, which are essential to the JPM, are summarized in Table 1.

\subsection{Calculation of storm rate}

The storm rate was determined using the method of Chouinard and Liu (1997). The omnidirectional rate is based on the distance of a storm from the location of interest X. Weights are assigned based on this information with storms making landfall close to $\mathrm{X}$ receiving greater weights than those making landfall further. Chouinard and Liu (1997) along with Niedoroda et al. (2010) use least-squares cross validation to determine the optimal balance between statistical precision and spatial bias, as is done in this study. The omni-directional rate was calculated to be $7.0163 \mathrm{E}-04$ storms $/$ year $/ \mathrm{km}$ at the Central Reference Point (CREF, defined to be Fort Myers Beach, FL) following this procedure. Due to the size of the domain, a single value is not representative of the entire coast. Values of the omnidirectional rate were determined every $9.3 \mathrm{~km}$ along the coast and show that the rate reaches a maximum near the CREF and decreases both to the north and south of this point. The rate was approximated with a seventh degree polynomial.

\subsection{Central pressure deficit}

The central pressure deficit for all 28 storms is examined. In some cases, the data are not available for all track locations. The model central pressure of Knaff and Zehr (2007) is used to compare with the available central pressure data. The model central pressure, which shows a strong correlation $\left(r^{2}=0.87\right)$ with the data, is used to fill in the missing data values. The values at landfall are fit to a variety of distributions and through maximum likelihood estimation are found to most closely fit a generalized extreme value (GEV) distribution (Kotz and Nadarajah 2000; Embrechts et al. 1997) with shape parameter of 0.3540 , scale parameter of 8.9801, and location parameter of 23.4782 .

\subsection{Radius to maximum winds}

Similar to the central pressure deficit data, the radius to maximum wind data is not complete for all records. A number of models are applied but the correlation between the available data and the model results is poor. As a result, only the available data are used.

For the radius to maximum winds, there is a documented correlation between $R_{\max }$ and pressure deficit (Shen 2006; Irish et al. 2008). This relationship is examined for the values at landfall for the storm sample and a weak negative correlation is found. The data are further examined to include all track positions in the Gulf of Mexico, where a stronger negative correlation between $R_{\max }$ and pressure deficit is determined especially for the storms with a central pressure deficit greater than $50 \mathrm{hPa}$. For the weaker storms, the distribution is best represented by a lognormal distribution. For the stronger storms, the relationship is similar to that obtained by Resio (2007) for a different segment of the Gulf of Mexico Coast. The conditional distribution of $R_{\max }$ for a given central pressure deficit (for central pressure deficit greater than $50 \mathrm{hPa}$ ) is described by a Lognormal distribution, based on the conditional mean of $R_{\max }=53.6236-0.41585 \Delta P$. 


\subsection{Forward speed}

The Weibull distribution (Devroye 1986) fits the forward speed data with the greatest MLE score. The location parameter for the Weibull distribution is 15.4562 and the shape parameter is 3.3798 .

\subsection{Storm heading}

The storm heading is represented as a GEV distribution with shape parameter of 0.3564 , scale parameter of 23.5194 , and location parameter equal to 26.9055 .

\section{Present flood hazard}

\subsection{Joint probability method}

The traditional JPM uses the probabilistic descriptions of storm rate and storm characteristics as done above to define a set of hypothetical storms (FEMA 1988). These hypothetical storms are used with a numerical storm surge model to calculate the coastal flood elevations that would be generated by each (Toro et al. 2010b). The annual rate of occurrence of a specific flood elevation at a point in excess of an arbitrary value $\eta$ is given by the JPM integral (Niedoroda et al. 2010):

$$
P\left[\eta_{\max }>\eta\right]=\lambda \int \cdots \int_{\underline{x}} f_{\underline{x}}(\underline{x}) P[\eta(\underline{x})>\eta] \mathrm{d} \underline{x}
$$

This is a function of the mean annual rate of all storms of interest for the site $\lambda$, the joint probability density function of the storm characteristics $f_{\underline{x}}(\underline{x})$, and the conditional probability that a storm of certain characteristics $\underline{x}$ will generate a flood elevation in excess of $\eta, P[\eta(\underline{x})>\eta]$; subscript $\max$ denotes an annual maximum value. The integral is evaluated for all possible storm parameter combinations. The result of the evaluation of the integral is a rate in terms of events per unit time, which is taken as the annual probability.

The multidimensional integral in Eq. 1 cannot be easily determined as written. Typically, it is approximated as a weighted summation of discrete storm-parameter values as (Niedoroda et al. 2010):

$$
P\left[\eta_{\max }>\eta\right] \sum_{i=1}^{n} \lambda_{i} P[\eta(\underline{x})>\eta]
$$

where each term in the summation corresponds to a synthetic storm with an annual rate of occurrence given by $\lambda i$. This approximation can be solved by simple quadrature such as the midpoint rule. However, to accurately integrate over the entire parameter space, tens of thousands of synthetic storms, with multiple values for each of the storm parameters, are needed. In practice, this is quite costly using advanced numerical models which can be computationally inefficient. To alleviate this problem, a set of optimal storms is developed using the optimal track generation technique (Condon and Sheng 2011). For this basin, under current climate conditions, a total of 197 optimal storms were determined. These storms are simulated using CH3D-SSMS as described above, and the envelope of high water (EOHW) for each storm is recorded. The EOHWs form the "training" dataset that is 
Table 2 Synthetic storm parameter values for traditional JPM

\begin{tabular}{lllll}
\hline$\Delta P(\mathrm{hPa})(P \mathrm{hPa})$ & $R_{\max }(\mathrm{km})$ & $V_{\mathrm{f}}(\mathrm{m} / \mathrm{s})$ & $\theta$ & $X_{\text {land }}$ \\
\hline $33(980)$ & 13 & 2.7 & $337.5^{\circ}$ & Spaced every 9.3 km from +370 to -222 \\
$53(960)$ & 26 & 5.4 & $0^{\circ}$ & relative to CREF (65 locations) \\
$73(940)$ & 39 & 8.0 & $22.5^{\circ}$ & \\
$93(920)$ & 52 & 10.7 & $45^{\circ}$ & \\
$113(900)$ & 65 & & $67.5^{\circ}$ & \\
& 78 & & $90^{\circ}$ & \\
\hline
\end{tabular}

combined with the multivariate adaptive regression spline technique of Friedman (1991) to obtain the inundation response for each of the 46,800 storms listed in Table 2. These storms represent possible storm parameter combinations spaced $9.3 \mathrm{~km}$ apart covering the basin. The storm parameter combinations were chosen based on review of past traditional JPM studies (i.e., Myers 1970, 1975; Ho 1974, 1975; Ho and Tracey 1975a, b, c; Ho et al. 1976) and expert analysis (personal communication, Donald Resio). The narrow spacing is important due to the high sensitivity of the surge response on the local topography and location of the storm track as described by Murty (1984).

The annual rate for each of the 46,800 storms was based on the statistical characterizations developed in Sect. 3 from the past hurricane climatology. The discretization of each storm parameter is shown in Table 3. The storm rate is determined based on the joint probabilities and the storm event rate for the location of landfall. The surge height for any return period is determined following the method of Niedoroda et al. (2010) accounting for errors due to the tide (standard deviation of $0.2 \mathrm{~m}$ based on Naples, FL tides) and the model (standard deviation of $15 \%$ of the modeled inundation height based on IOOS Testbed results).

\subsection{Results}

Analysis of the present day hazard shows that much of the area is susceptible to hurricaneproduced storm surge and inundation (Fig. 4). The inundation in all figures is in excess of $30.5 \mathrm{~cm}$ ( $\sim 1$ foot), in accordance with designation of Special Flood Hazard Area by FEMA (2003). The 10-year inundation hazard is contained almost exclusively to the southern portion of the domain and along the rivers and bays. Although the southern portion contains the Florida Everglades and there is little or no development, there is considerable coastal development along the rivers and bays that are susceptible to low return period events. The higher return periods show much larger flooded area. Figure 5 shows metrics to better quantify the extent of the inundation for each return period by reflecting areas that receive at least $30.5 \mathrm{~cm}(\sim 1$ foot). The 100-year BFE produced in this study is based on the optimal hurricane ensemble that accurately represents the hurricane climatology and hence should be more accurate than the existing FEMA 100-year BFE which was produced without using the optimal hurricane ensemble.

The total just value (legally synonymous with 'Market Value' in Florida) is used as a descriptor of the economic cost associated with each event. This gives a good representation of the actual value of the property and is obtained from 2009 parcel data for each county from the Florida Geographic Data Library (FGDL 2010). The just value of affected property for a given inundation event is determined by combining the total just value for a parcel with the percentage of damage from USACE depth-damage curves (2006). The 
Table 3 Synthetic storm parameter discretized probability values (weights)

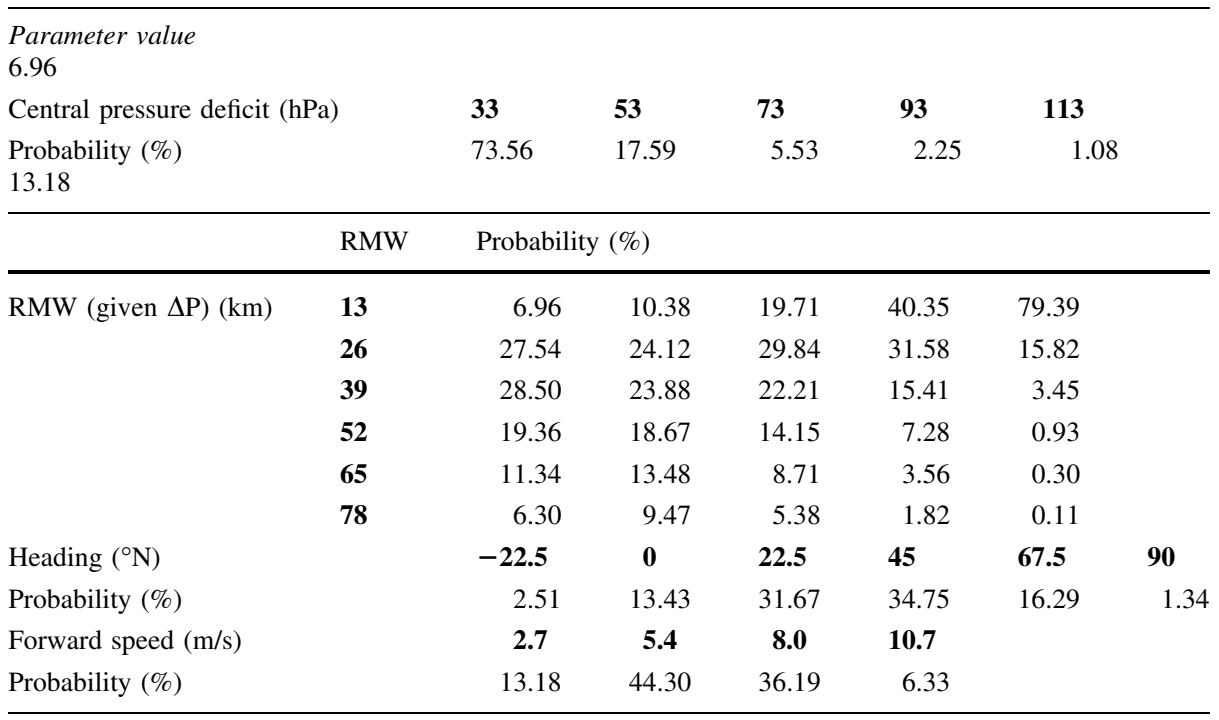

The bold numbers are the category values. Central pressure deficits of 33, 53, 73, 93 and $113 \mathrm{mb}$ and the normal type is the probability associated with each

same FGDL database contains information regarding the population distribution throughout the domain based on 2010 census data. It should be noted that it is extremely unlikely that a certain inundation event will affect the entire domain at the same time. The flooded volume, area, the affected population, and the just value of the affected property of a single hurricane will likely be less than that depicted in Fig. 5 and so the associated return period will likely not occur at the same time throughout the domain. For example, the just value calculated in this way for Hurricane Wilma in 2005 is about \$3.6 billion, affecting 26,000 people with a flooded volume of $2.59 \mathrm{~km}^{3}$ and flooded area of just under $2,000 \mathrm{~km}^{2}$. By comparison with the values in Fig. 5, the inundation metrics from a single storm will likely be much less, since the Figure represents the inundation event across the entire domain, which will likely not occur during a single storm event. Nevertheless, the results in the Figure are consistent with the way probabilistic flood maps are presented. Such information is more useful for long-term planning, while information for a single storm might be more useful for planning for a single approaching storm.

The 50-, 100-, and 500-year storms all would result in over $2,500 \mathrm{~km}^{2}$ of property being affected. The 500 -year storm could affect up to $\$ 24$ billion worth of property and over 600,000 lives (Fig. 5). The 100-year storm, which is the basis for flood insurance rate maps, shows extensive inundation in almost all portions of the domain. As an example of a way to quantify the risk of inundation, an inundation risk map (Fig. 6) is produced by considering wave heights and water velocity, in addition to surge height, as recommended by NRC (2009). By including velocity data, the consequences of the flood hazard on a structure can be determined which produces the risk map. The inundation risk map is constructed by placing all areas that are within the 10-year flood zone in the extreme-risk category. The high-risk category consists of those areas in the 50-year flood zone or those that fall in the 100-year flood zone and meet the FEMA velocity zone characteristics (Wave height of 0.64 meter or the product of depth of flow times the flood velocity squared 

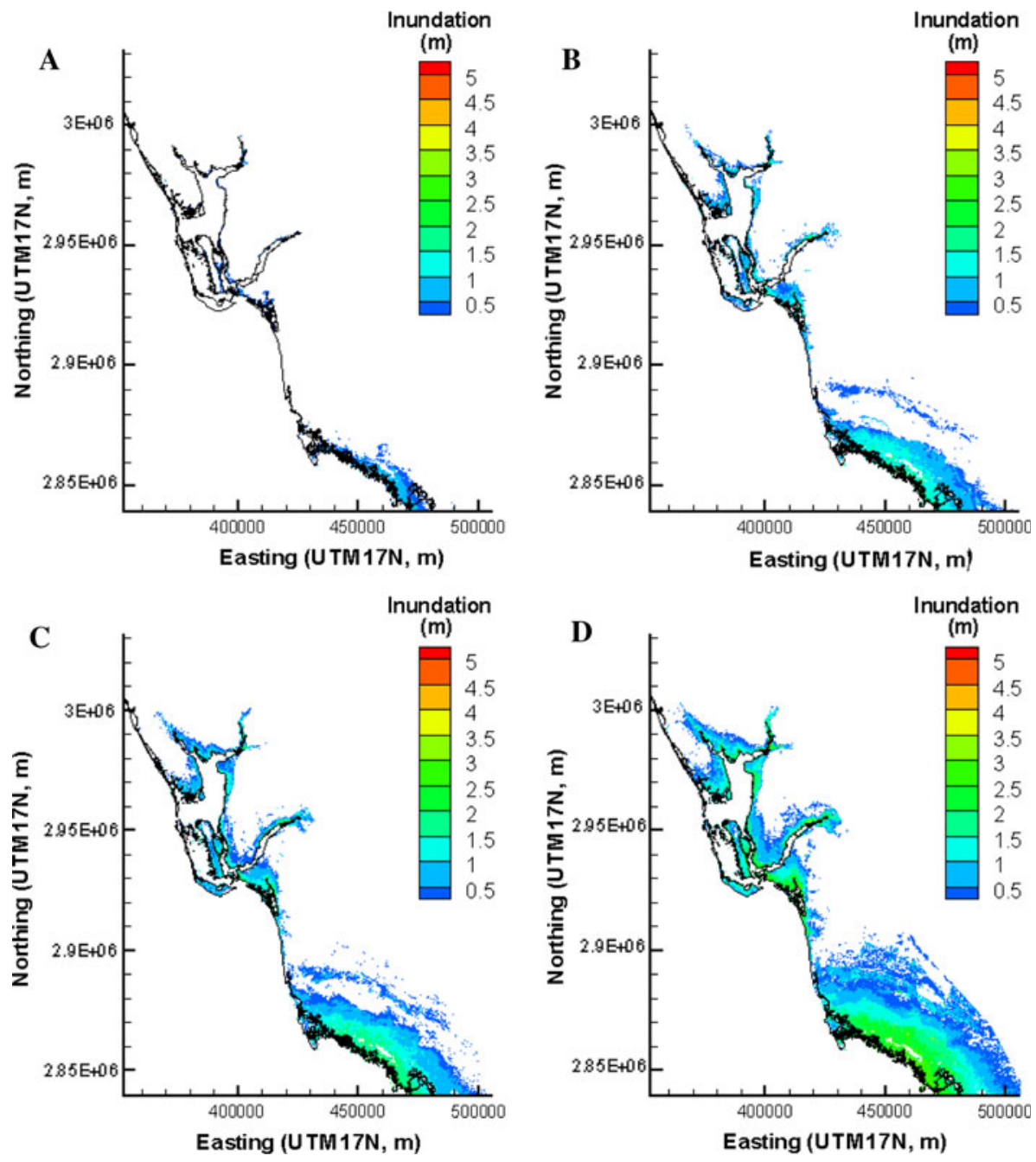

Fig. 4 Expected inundation (exceeding $30.5 \mathrm{~cm}$ ) under present day conditions for the 10-year (a), 50-year (b), 100-year (c), and 500-year (d) return periods

is greater than or equal to $5.66 \mathrm{~m}^{3} / \mathrm{s}^{2}$ ) (FEMA 2007). The medium-risk zone consists of the rest of the 100-year flood zone, and the low-risk zone is made up of the 500-year flood zone. This map shows that most of the immediate coastline is in the high or greater category. As expected, the areas around the low-lying Everglades, the barrier islands and beaches, and near the rivers and bays are at the greatest risk.

\section{Future flood hazard}

As was done for the current day flood hazard assessment, the future hazard from storm surge can be determined with adjustments to the problem to reflect changes in hurricane activity and sea level rise (SLR) due to a warming climate. 
Fig. 5 Risk map for present day sea level and hurricane conditions for Southwest FL, created by accounting for velocity, wave and inundation data

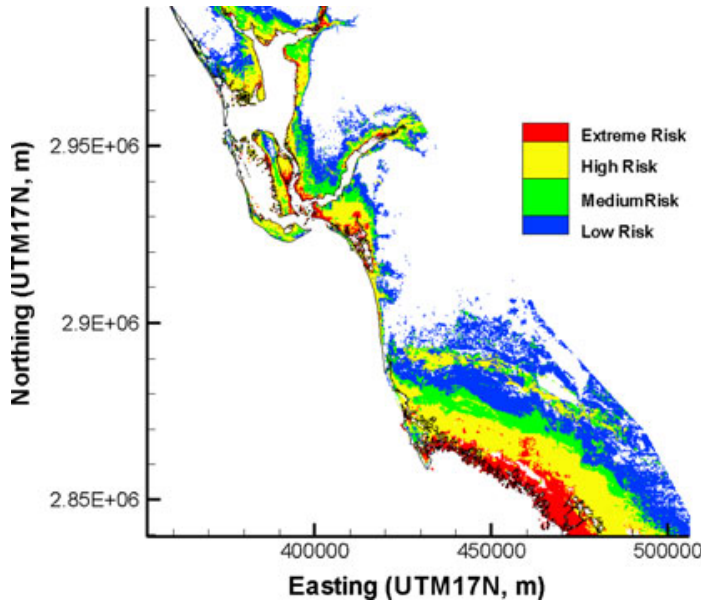

\subsection{Climate change and hurricanes}

The effect of a warmer climate on hurricanes is still uncertain (Knutson et al. 2010). In a warming climate, sea surface temperatures (SSTs) are expected to rise across the Atlantic (Meehl et al. 2007). SST has long been acknowledged as one of the key factors that influence hurricane formation (Gray 1979) and the maximum intensity (Emanuel 1987). While global climate models have reached a consensus that SST will increase over the next century (Emanuel et al. 2008), models have also concluded that vertical wind shear in the atmosphere will increase as well (Vecchi and Soden 2007; Wang and Li 2008). These two components act to negate each other which make future predictions somewhat uncertain. Based on recent results obtained with finer resolution global climate models and downscaled high resolution regional models, a group of leading climate and hurricane scientists have reached a consensus estimate that, by 2100, globally averaged hurricane wind intensity will increase by $2-11 \%$ (central pressure deficit by $3-21 \%$ ) and the globally averaged frequency of hurricanes will decrease between 6 and 34\% (Knutson et al. 2010).

The above projections are used to define future scenarios by adjusting the probabilistic descriptions for the current day climatology. A "worst-case", "best-case", and "midrange" scenario are developed as shown in Table 4. The storm intensity (central pressure deficit) is modeled as a GEV function which falls into the class of extreme value functions and is parameterized by a location, scale, and shape parameter. Katz and Brown (1992) showed that non-stationarity (i.e., climate change) can be modeled probabilistically by changing the function parameters. In the case of the GEV distribution for central pressure deficit, a linear time-dependent trend, resulting in the corresponding percent increase in the scenario by 2100 , is applied to the location and scale parameter that estimates the change due to climate change (Fig. 7a). For the storm frequency, the percent change for the scenario is applied to each location where the storm rate is calculated and a new fit for the rate is determined (Fig. 7b).

\subsection{Sea level rise}

Similar to the projections of future hurricane intensity, the literature is full of debate on what future sea level rise may be. Vermeer and Rahmstorf (2009) predict 75 to $190 \mathrm{~cm}$ of 
Fig. 6 Risk metrics for the 10-, 50-, 100-, and 500-year inundation events for scenarios defined in Table 4. All statistics reflect inundation greater than $30.5 \mathrm{~cm}$ ( 1 foot). Affected population is relative to 2010 census data. Total just value data based on just value of real property as of 2009
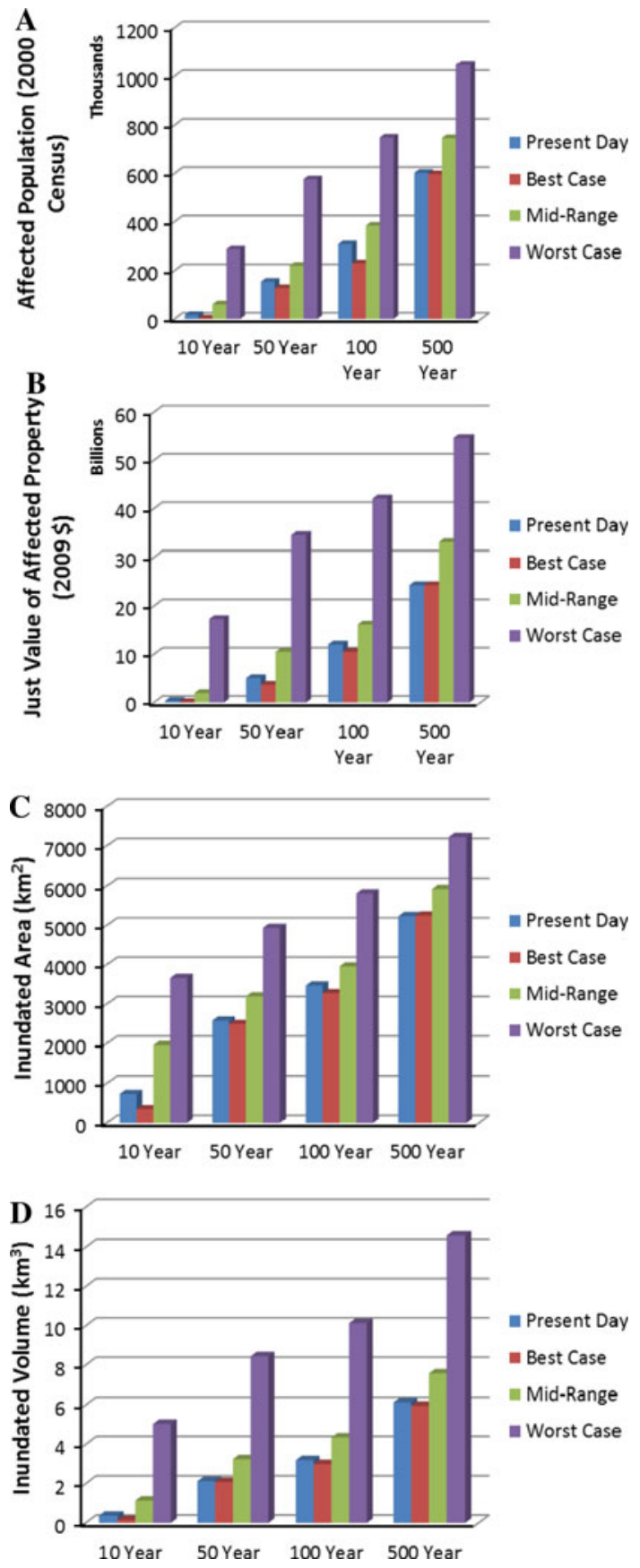

sea level rise over the next century-a large increase over most other projections including the IPCC Fourth Assessment Report (Meehl et al. 2007) which projects sea level to rise $18-59 \mathrm{~cm}$ globally. Analysis of the past records has shown conflicting views as well. 
Table 4 Scenarios used for evaluation of the inundation hazard in future climate

\begin{tabular}{llll}
\hline & Worst case & Best case & Mid-range \\
\hline Hurricane intensity & $+21 \%$ & $+3 \%$ & $+12 \%$ \\
Hurricane frequency & $-6 \%$ & $-34 \%$ & $-20 \%$ \\
SLR & $+150 \mathrm{~cm}$ & $+21 \mathrm{~cm}$ & $+50 \mathrm{~cm}$ \\
\hline
\end{tabular}
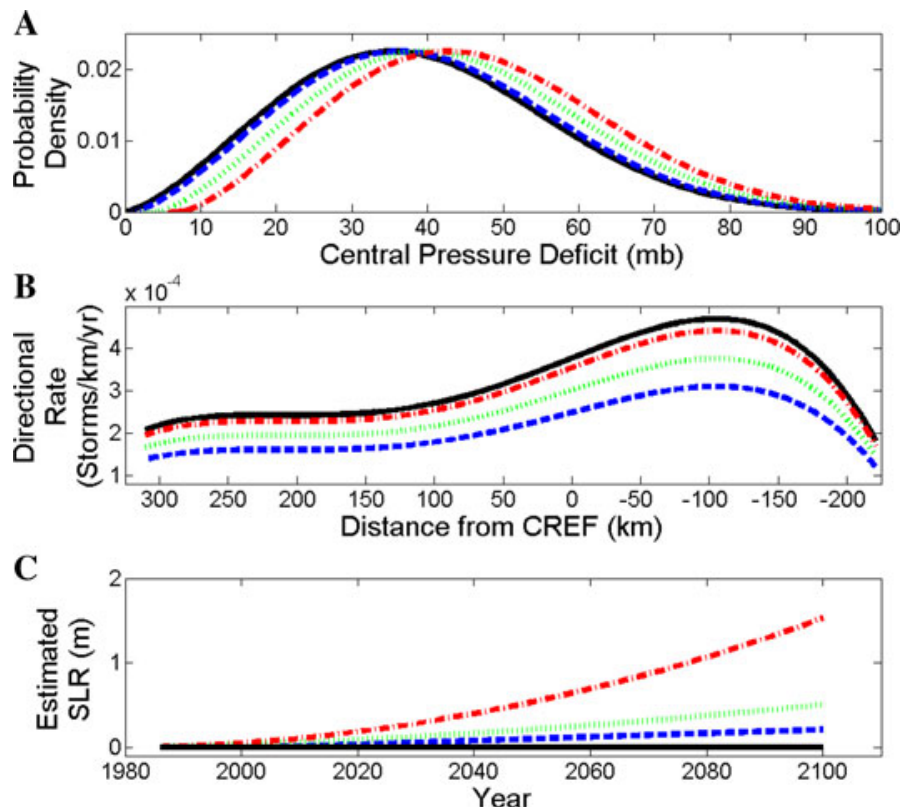

Fig. 7 Projected changes to storm intensity (a), frequency (b), and sea level rise (c) for present day conditions (black line) and three future climate scenarios (Best-case scenario-blue dotted; Mid-range scenario-green dotted; and worst-case scenario-red dotted)

Douglas (1991) concluded that there was a slight deceleration in global mean sea level rise, while Church and White (2006) found a slight acceleration in global records. More recently, Houston and Dean (2011) found that SLR is currently not accelerating at a pace necessary to reach the estimates of the IPCC and Vermeer and Rahmstorf. With so much uncertainty, we consider three sea level change scenarios: (1) a continuation of the "low" $(21 \mathrm{~cm})$ mean trend based on estimates from NOAA Tides and Currents (2010) of the trend in mean sea level for stations near the central reference point; (2) an "intermediate" $(50 \mathrm{~cm})$ prediction (Meehl et al. 2007; NRC 2010); and (3) a "high" (150 cm) prediction (Meehl et al. 2007; Vermeer and Rahmstorf 2009; NRC 2010; Rahmstorf 2010). The sea level rise scenarios are shown in Fig. 7c. The SLR scenarios are modeled by adjusting the mean offshore sea level, allowing it to equilibrate and running the simulations. It is recognized that the bathymetry/topography, land use, barrier islands, etc. will likely change in the next 90 years from their present condition; however, it is beyond the scope of this paper to simulate those changes. Local variations in SLR can also be important. An analysis of tide stations on Florida's west coast with at least 60 years of water level data shows that the local trend is between $1.8 \mathrm{~mm}_{\text {year }}{ }^{-1}$ (Cedar Key) and $2.24 \mathrm{~mm}_{\text {year }}{ }^{-1}$ 
(Key West). These rates are just slightly higher than the globally averaged rate of about $1.7 \mathrm{~mm} \mathrm{year}^{-1}$ (Meehl et al. 2007). Taking an average of the two rates and projecting out to 2100 , the local affect is about $3 \mathrm{~cm}$. Given the large uncertainty in the SLR estimates, the local contribution is considered small and the above scenarios are used.

\subsection{Results}

With the above changes in place, new simulations in CH3D-SSMS are carried out with the appropriate changes to sea level and with new optimal storms that reflect the changes in sea level. Figure 8 shows the spatial extents for the inundation for each scenario and return period. Figure 8a summarizes the current day scenario as presented above. Figure $8 \mathrm{~b}$ shows the best-case future scenario. This scenario features a large reduction in the storm rate and only a slight increase in storm intensity, which is reflected by a reduction in the area affected by the short-term inundation events. The increase in intensity and the small increase in sea level are enough to create an increase in flooded area over the present day for the 500-year event (Fig. 5). However, for all other events, the flooded area is less, as is the affected just value and population. For all cases, the flooded volume is less than the current day value.

Figure $8 \mathrm{c}$ shows the spatial extents of various return periods for the mid-range climate change scenario. For all return periods, this represents an increase over the current day scenario. The biggest increase is in the low return period event. The flooded volume for the 10 -year storm is more than double that of the present day. This is in large part due to the additional inundation created by the $50 \mathrm{~cm}$ of SLR. The 500-year storm for this scenario will affect nearly 750 thousand people and up to $\$ 33$ billion worth of property (as defined above to equal or exceed inundation of $30.5 \mathrm{~cm}$ ).

The worst-case future scenario depicted in Fig. $8 \mathrm{~d}$ shows a very alarming situation. The inundated area increases by over 2.5 times the current day area for the 10 -year event. This is largely due to the loss of land caused by the $150-\mathrm{cm}$ SLR, but also as a result of the shift to more intense hurricanes. In this scenario, the 100-year event, which is the basis for the FIRM, shows that over 675 thousand people will be affected by at least $30.5 \mathrm{~cm}$ of inundation. This demonstrates that the worst-case future scenario would lead to a dramatic increase in the requirement of flood insurance with a large portion of the residents of SW FL meeting that requirement.

To attempt to separate the influences of sea level rise from those in changes in hurricanes, the three hurricane scenarios are run for present day sea level. Figure 9 shows the spatial extents as depicted in Fig. 8, but at present day sea level. Figure 10 shows the same metrics as presented in Fig. 5. From this figure, it is clear that sea level rise poses the greatest hazard to inundation. Without consideration of sea level rise, likely changes in hurricane characteristics do not produce a large increase in the inundation hazard. Only the worst-case scenario, which features a large increase in hurricane intensity coupled with a slight decrease in hurricane frequency, produces metrics which show a greater hazard than is currently experienced.

The influence of the sea level rise can be demonstrated with a MOM for the category 5 storm (taken here as a central pressure deficit of $100 \mathrm{hPa}$ ). The same optimal storm database is used to construct the category 5 MOM depicted in Fig. 11 for the present day (a), with $21 \mathrm{~cm}$ of sea level rise (b), with $50 \mathrm{~cm}$ of sea level rise (c), and with $150 \mathrm{~cm}$ of sea level rise (d).

The technique described here differs from that used in many previous studies (Frazier et al. 2010; Kleinosky et al. 2007; Wu et al. 2002) dealing with SLR and hazard from storm 

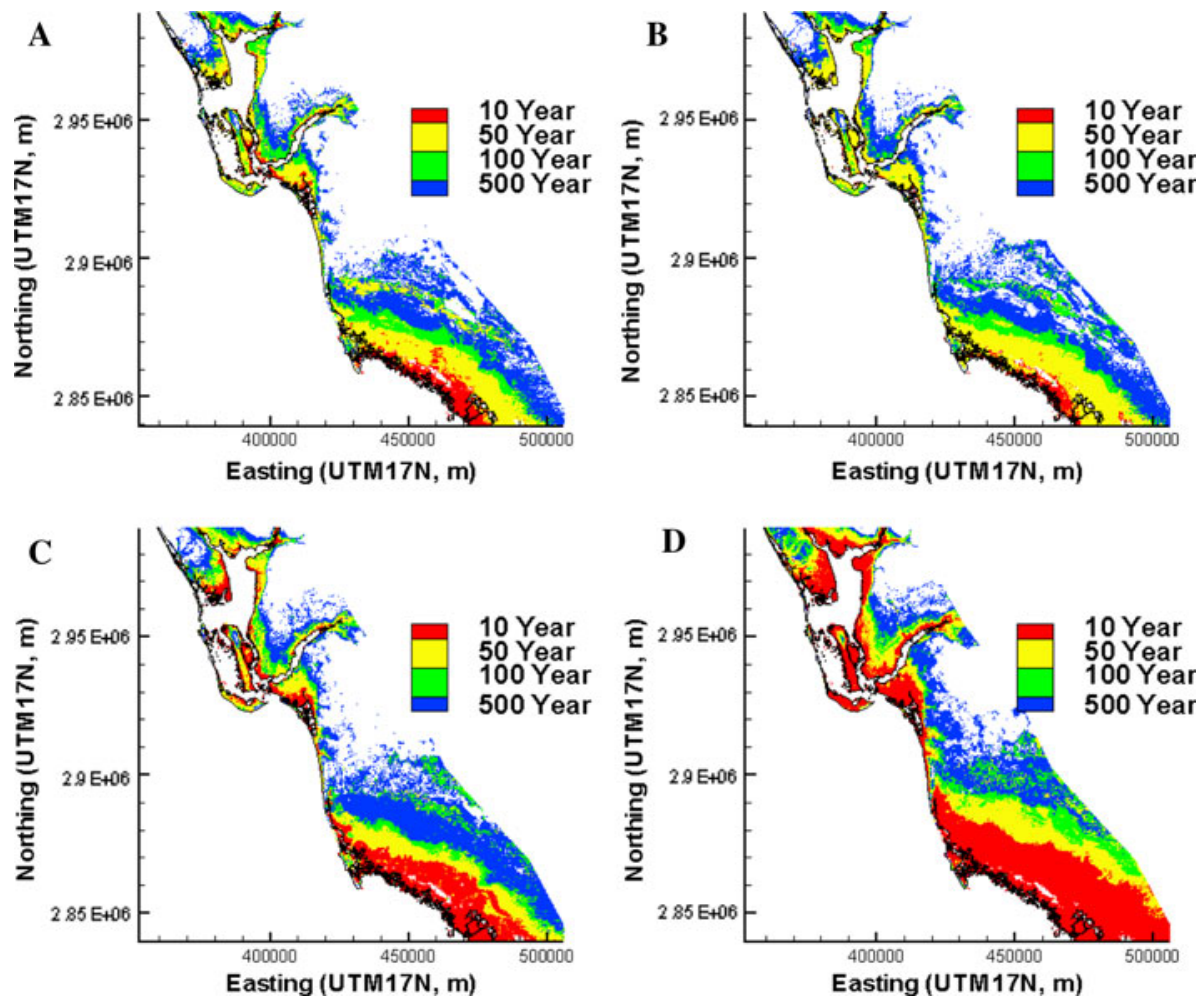

Fig. 8 Spatial extents for the 10-, 50-, 100-, and 500-year inundation events for present day (a), Best-case future scenario (b), mid-range future scenario (c), and worst-case future scenario (d)

surge. The current study applies the SLR at the open boundary and allows it to propagate in where the influence of the topography is accounted for in the surge response, while the three previous studies simply adjusted the topography a set amount corresponding to the specified SLR - this excludes the interaction between the surge and the bathymetry/ topography and results in different inundation levels. Figure 12 shows the Category 5 MOM with $150 \mathrm{~cm}$ of SLR using a coastal model (our technique) (a) and the previously published technique (b), as well as the differences between the two MOMs (c). The previously used technique tends to overestimate the surge in most areas with the exception of the low-lying Everglades where resistance to the surge is very weak. Based on this comparison, it is clear that more robust methods, such as those employed in this study, be used for accurate evaluation of the inundation threat due to SLR.

\section{Conclusion}

A detailed analysis of the inundation hazard to Southwest Florida has been presented. This analysis is developed by a combination of optimal storm generation, numerical storm surge and inundation simulation, and multivariate interpolation. The CH3D-SSMS model results are used to determine the BFE. In addition, metrics are produced to better quantify the 

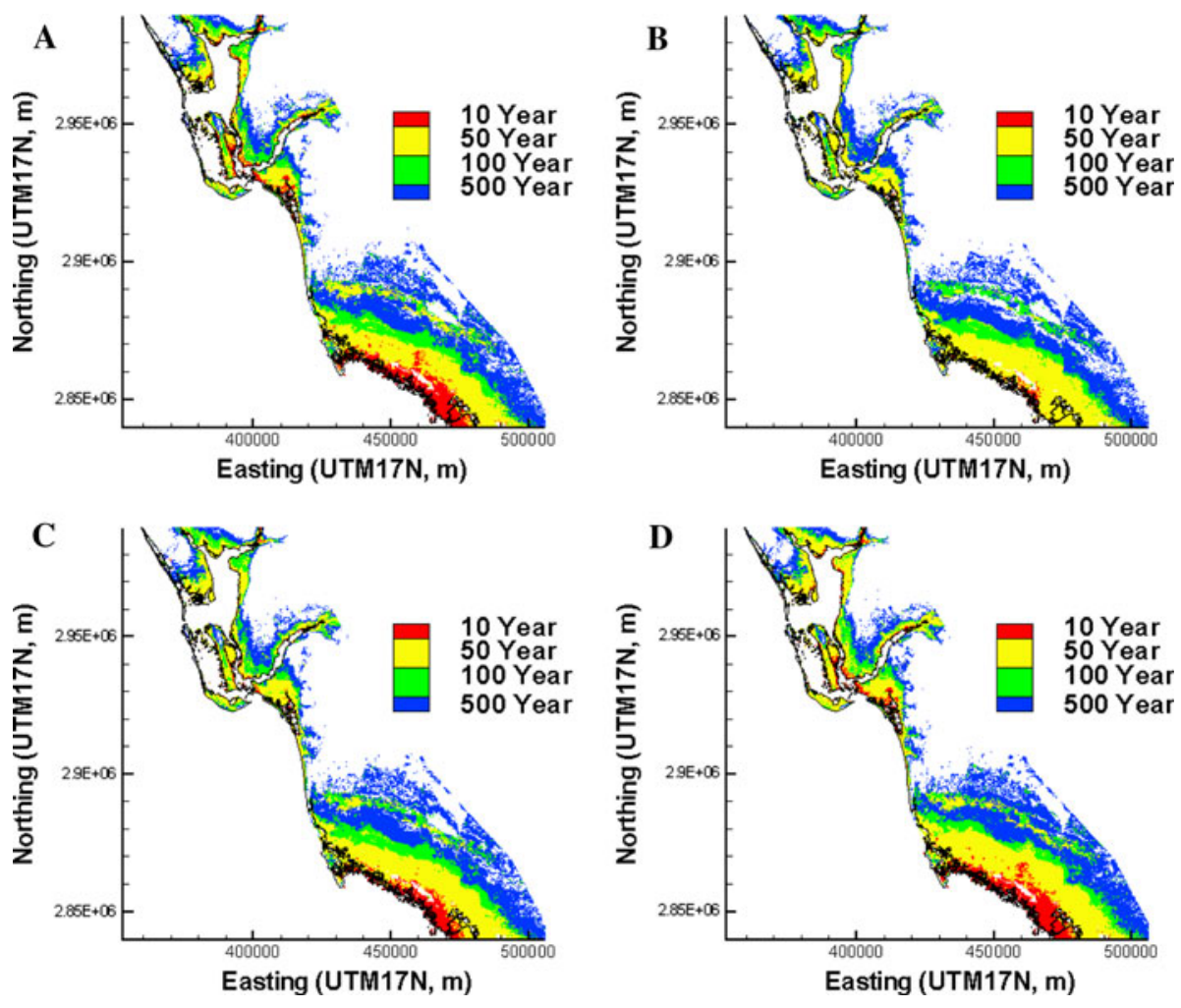

Fig. 9 Spatial extents for the 10-, 50-, 100-, and 500-year inundation events for present day (a), Best-case future scenario (b), mid-range future scenario (c), and worst-case future scenario (d)

damage from a given surge event in terms of the number of people affected and the cost of the event as well as flooded area and volume. Using the optimal hurricane ensemble to better represent the hurricane climatology, this study produces more accurate BFE for the Southwest Florida region than that produced by FEMA without using the optimal hurricane ensemble.

This work sought to answer the following questions: (1) How will the coastal hazard maps for future climate differ from that for the present climate, and why? (2) How does a coastal hazard map produced in this study differ from that produced without using a coastal storm surge model? (3) What will a coastal inundation hazard map look like? (4) What is the hazard of coastal inundation induced damage on coastal property and population? The answers to these questions can be summarized as:

1. The hazard in future climate will be greater throughout the region due mainly to SLR. When SLR is not considered, there is little change in hazard over the present day as it appears that the projected decrease in hurricane frequency mostly offsets the increase in hurricane intensity.

2. There are large differences in coastal hazard maps generated using a modeling system to account for SLR and one produced by simply changing the underlying elevation data to account for SLR to a pre-existing inundation map. The modeling system allows 
Fig. 10 Risk metrics for the 10-, 50-, 100-, and 500-year inundation events for hurricane scenarios defined in Table 4 but at present day sea level. All statistics reflect inundation greater than $30.5 \mathrm{~cm}$ ( $\sim 1$ foot). Affected population is relative to 2010 census data. Total just value data based on just value of real property as of 2009
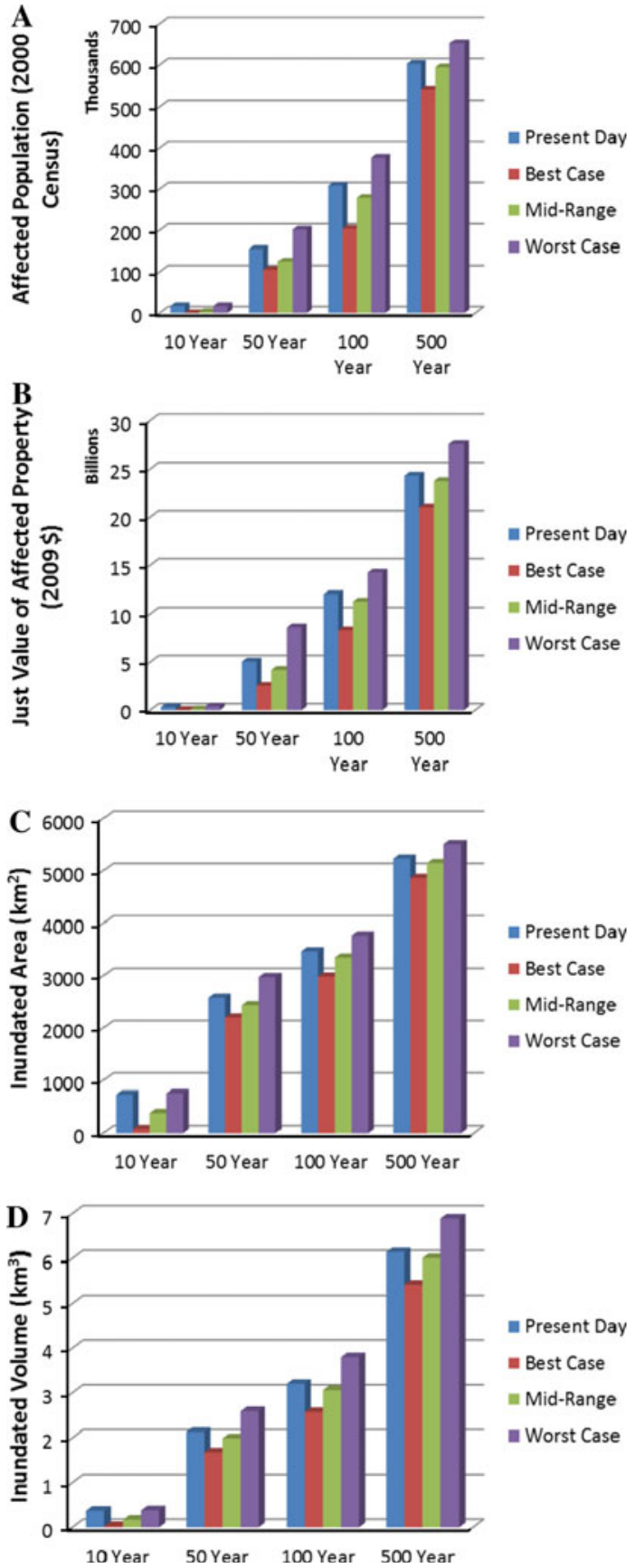

for interaction between the inundation and the topography which leads to dissipation of inundation and generally lower inundation values.

3. The hazard maps vary depending on the climate (current or future) and the return period. In general, the low-lying region around the Everglades and near the rivers and 

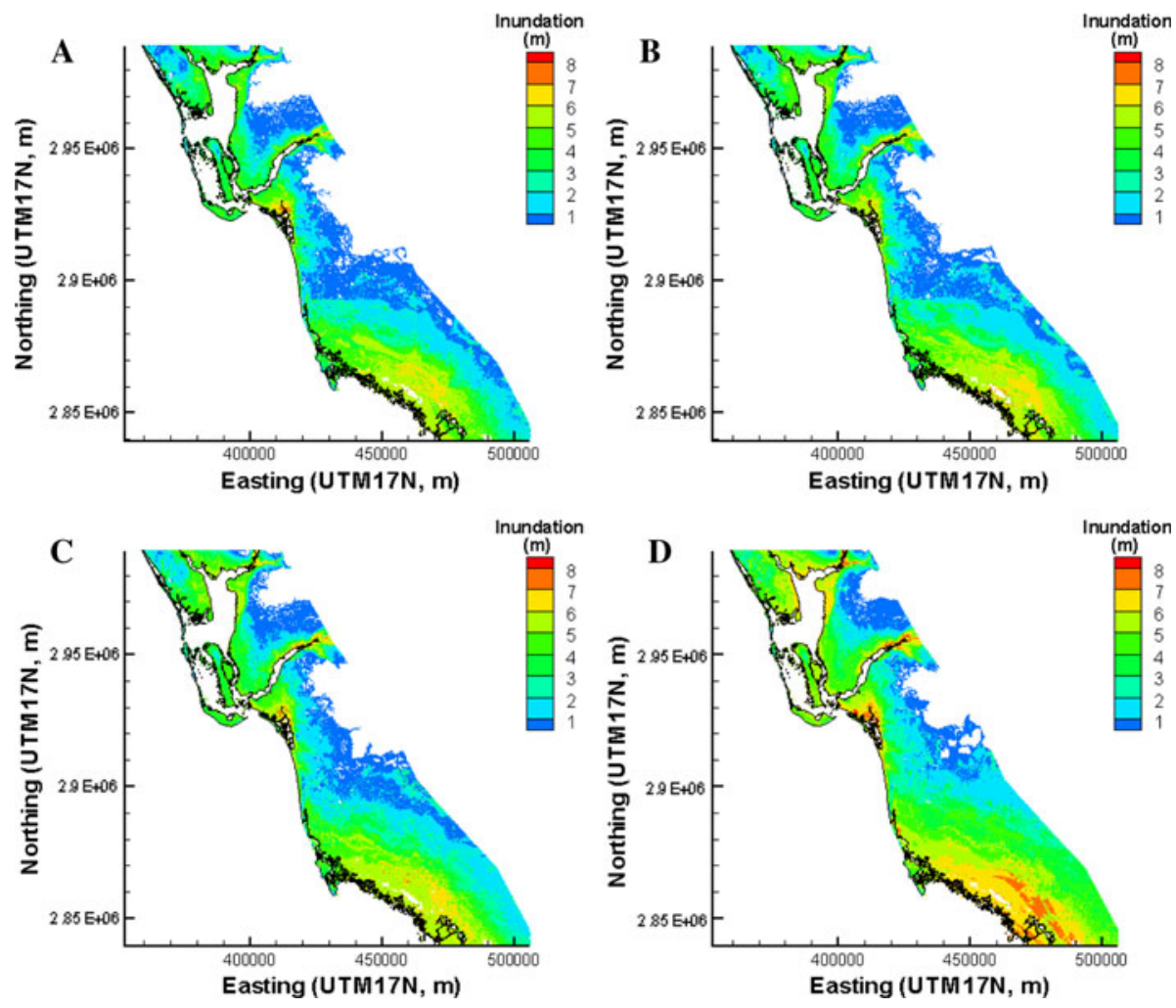

Fig. 11 Category 5 MOM for present day sea level (a), $21 \mathrm{~cm}$ of SLR (b), $50 \mathrm{~cm}$ of SLR (c), and $150 \mathrm{~cm}$ of $\operatorname{SLR}(\mathbf{d})$

bays are most susceptible to inundation. As the frequency of the event becomes lower, the area of inundation increases to where the 500-year event covers-much of the heavily populated areas near Fort Myers, the islands, and around Charlotte Harbor.

4. Although these events are unlikely to influence the entire region during a single storm, the population and property affected by the events are significant due to the concentration of real property and population in the coastal regions. Figures $6 \mathrm{a}, \mathrm{b}$ and $10 \mathrm{a}, \mathrm{b}$ quantify these values for different scenarios and for different return periods.

These results are more useful for planning purposes than results associated with a single storm.

For future work, spatial variability in sea level rise (e.g., Yin et al. 2010) should be considered. As sea level rise predictions become more regional, the broadly defined scenarios presented here can become more finely tuned for a specific region. In addition, as prediction of changes in hurricane frequency and intensity becomes less uncertain over time, it will be worthwhile to revisit the topics of this paper. The estimates used herein are based on global estimates. As basin and smaller scale results become available through down-scaling, more accurate depictions of the hazard due to climate change can be developed. Future work can also be conducted to better quantify the correct cut-off depth 
Fig. 12 Category $5 \mathrm{MOM}$ for $150 \mathrm{~cm}$ of SLR using technique described herein (a) category 5 MOM for $150 \mathrm{~cm}$ of SLR using simple subtraction of $150 \mathrm{~cm}$ from base topography (b), difference between $\mathbf{b}$ and $\mathbf{a}$ (c)
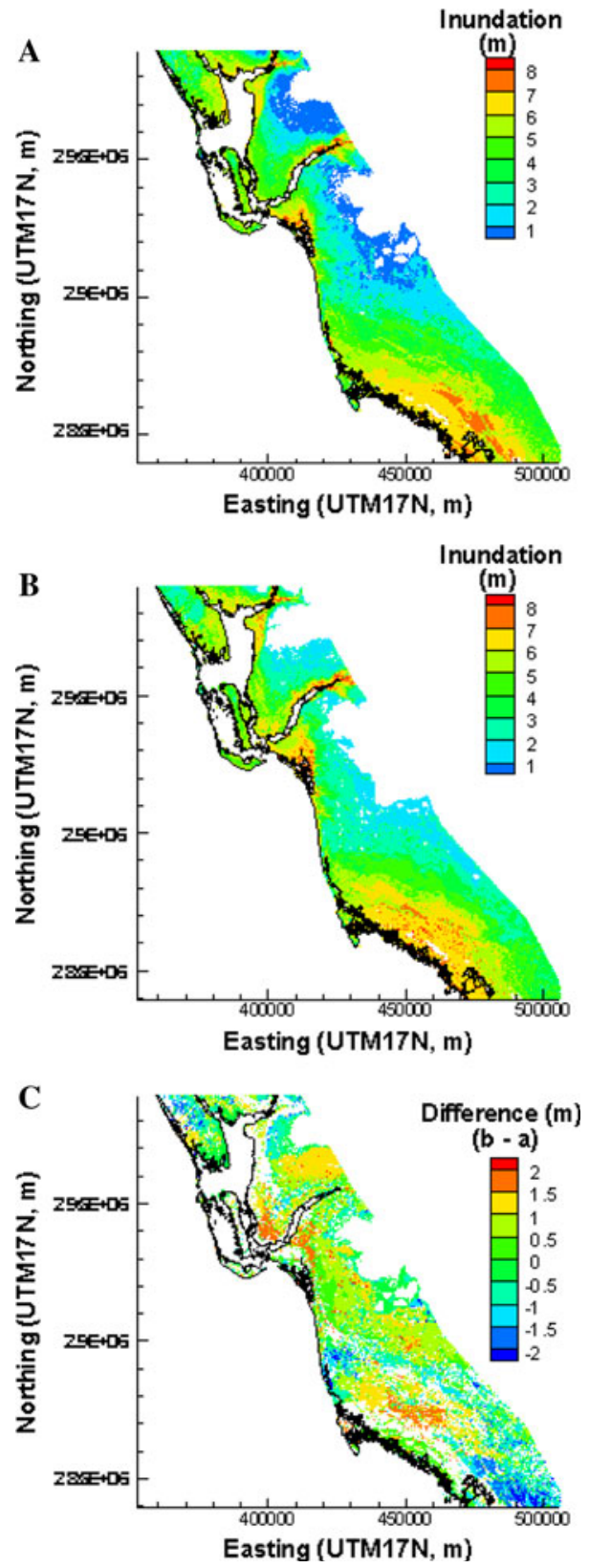

for areas affected by inundation. As mentioned earlier, one foot was used in this study as was done by FEMA in designation of SPHA, but no scientific information supporting this value is readily available.

With some effort, the information produced by this study can be incorporated into future coastal planning, coastal construction, and evacuation planning in many different coastal zones in the coming years. 
Acknowledgments YPS would like to acknowledge the partial final support of a NOAA/IOOS Grant-A Regional Storm Surge and Inundation Model Testbed (Award Number NA07NOS4730211). AJC was supported by a National Defense Science and Engineering Graduate (NDSEG) Fellowship, 32 CFR 168a, as well as a University of Florida Alumni Fellowship. The authors would like to acknowledge Dr. Donald T. Resio and Dr. Senanu Agbley for their assistance on the JPM-OS method, and Florida Division of Emergency Management and National Hurricane Center for providing LIDAR data and SLOSH data for Southwest Florida.

Open Access This article is distributed under the terms of the Creative Commons Attribution Noncommercial License which permits any noncommercial use, distribution, and reproduction in any medium, provided the original author(s) and source are credited.

\section{References}

Agbley S (2009) Towards the efficient probabilistic characterization of tropical cyclone-generated storm surge hazards under stationary and non-stationary conditions. PhD. dissertation, Civil Engineering, Old Dominion University, Norfolk, VA, USA

Agbley S, Basco D (2008) An evaluation of storm surge frequency-of-occurrence estimators. Paper presented at Solutions to Coastal Disasters, ASCE, Turtle Bay, Hawaii, USA

Ali A (1996) Vulnerability of Bangladesh to climate change and sea level rise through tropical cyclones and storm surges. J Water Air Soil Pollut 92:171-179

Ali A (1999) Impacts and adaption assessment in Bangladesh. Clim Res 12:109-116

Blake ES, Rappaport EN, Landsea CW (2007) The deadliest, costliest, and most intense United States Tropical Cyclones from 1851 to 2006. National Weather Service: National Hurricane Center

Bleck R (2002) An oceanic general circulation model framed in hybrid isopycnic- Cartesian coordinates. Ocean Model 4:55-88

Booij N, Ris RC, Holthuijsen LH (1999) A third-generation wave model for coastal regions: 1. Model description and validation. J Geophys Res 104(C4):7649-7666

Chouinard LE, Liu C (1997) A model for the severity of hurricanes in the Gulf of Mexico. J Waterw Harb Coast Eng 123:113-119

Church JA, White NJ (2006) A 20th century acceleration in global sea-level rise. Geophys Res Let 33(L01602). doi:10.1029/2005GL024826

Condon AJ, Sheng YP (2011) Optimal storm generation for evaluation of the storm surge inundation threat. Technical Report 2011-05, Coastal and Oceanographic Engineering, University of Florida, Gainesville, FL, $43 \mathrm{pp}$

Danard M, Munro A, Murty T (2003) Storm surge hazard in Canada. Nat Hazards 28:407-431

Davis JR, Paramygin VA, Sheng YP (2008) On the use of probabilistic wind fields for the forecast of storm surge and inundation in Charlotte Harbor, FL. In: Proceedings of the 10th Int'l conference on estuarine and coastal modeling, ASCE, Reston, VA, pp 447-466

Davis JR, Paramygin VA, Forrest D, Sheng YP (2010) Probabilistic simulation of storm surge and inundation in a limited resource environment. Mon Wea Rev 138(7):2953-2974

Devroye L (1986) Non-uniform random variate generation. Springer, New York

Divoky D, Resio DT (2007) Performance of the JPM and EST methods in storm surge studies. In: 10th International workshop on wave hindcasting and forecasting and coastal hazard symposium. Joint WMO/IOC technical commission for oceanography and marine meteorology, Oahu, Hawaii, USA

Douglas BC (1991) Global sea level rise. J Geophys Res Oceans 96(C4):6981-6992. doi:10.1029/91JC00064

Emanuel KA (1987) The dependence of hurricane intensity on climate. Nature 326:483-485

Emanuel KA (2005) The increasing destructiveness of tropical cyclones over the past 30 years. Nature 436:686-688

Emanuel K, Sundararajan R, Williams J (2008) Hurricanes and global warming: results from downscaling IPCC AR4 simulations. Bull Am Meteor Soc 89:347-367

Embrechts P, Klüppelberg C, Mikosch T (1997) Modelling extremal events for insurance and finance. Springer, New York

Federal Emergency Management Agency (1988) Coastal flooding hurricane storm surge model: methodology, vol 1, Washington, DC

Federal Emergency Management Agency (2003) Guidelines and specifications for FEMA flood hazard mapping partners. Volume 1, Flood studies and mapping. Washington, DC, April, 2003 
Federal Emergency Management Agency (2007) Atlantic ocean and Gulf of Mexico coastal guidelines update, Final Draft. Washington, DC, February, 2007

Federal Emergency Management Agency (2008) Mississippi coastal analysis project. Project reports prepared by URS Group INC. (Gaithersburg MD and Tallahassee FL) under HMTAP Contract HSFEHQ06-D-0612, Task Order 06-J-0018

Feyen JC, Hess KW, Spargo EA, Wong A, White SA, Sellars J, Gill SK (2006) Development of a continuous bathymetric/topographic unstructured coastal flooding model to study sea level rise in North Carolina, Estuarine and Coastal Modeling. Proceedings of the ninth international conference, ASCE, Reston, VA, pp 338-356

Florida Geographic Data Library (2010) Data download. http://www.fgdl.org/download/index.html. Accessed on 15 Sep 2010

Frazier TG, Wood N, Yarnal B, Bauer DH (2010) Influence of potential sea level rise on societal vulnerability to hurricane storm-surge hazards, Sarasota County Florida. App Geo 30:490-505

Frey AE, Olivera F, Irish JL, Dunkin LM, Kaihatu JM, Ferreira CM, Edge BL (2010) Potential impact of climate change on hurricane flooding inundation, population affected and property damages in Corpus Christi. J Am Water Res Assoc 46(5):1049-1059

Friedman J (1991) Multivariate adaptive regression splines. Ann Stats 19:1-141

Gerstner T, Griebel M (2003) Dimension-adaptive tensor product quadrature. Computing 71:65-87

Goldenberg SB, Landsea CW, Mestas-Nunez AM, Gray WM (2001) The recent increase in Atlantic hurricane activity: causes and implications. Science 293(5529):474-479

Gray WM (1979) Hurricanes: Their formation, structure and likely role in the tropical circulation. In: Shaw DB(ed) Meteorology over the Tropical Oceans Roy. Meteor. Soc, James Glaisher House, Grenville Place, Bracknell, Berkshire, RG12 1BX, pp 155-218

Grinsted A, Moore JC, Jefrejeva S (2009) Reconstructing sea level from paleo and projected temperatures 200 to 2100 ad. Clim Dyn 34:461-472

Halliwell GR Jr, R Bleck, Chassignet E (1998) Atlantic ocean simulations performed using a new Hybrid Coordinate Ocean Model (HYCOM). EOS, Fall AGU Meeting

Halliwell GR Jr, Bleck R, Chassignet EP, Smith LT (2000) Mixed layer model validation in Atlantic Ocean simulations using the Hybrid Ocean Model (HYCOM). EOS 80:OS304

Ho FP (1974) Storm tide frequency analysis for the coast of Georgia. NOAA Technical Memo NWS Hydro19. US Department of Commerce, Washington, DC, $28 \mathrm{p}$

Ho FP (1975) Storm tide frequency analysis for the coast of Puerto Rico. NOAA Technical Memo NWS Hydro-23. US Department of Commerce, Washington, DC, $43 \mathrm{p}$

Ho FP, Tracey RJ (1975a) Storm tide frequency analysis for the Gulf coast of Florida from Cape San Blas to St. Petersburg Beach. NOAA Technical Memo NWS Hydro-20. US Department of Commerce, Washington, DC, $34 \mathrm{p}$

Ho FP, Tracey RJ (1975b) Storm tide frequency analysis for the coast of North Carolina, south of Cape Lookout. NOAA Technical Memo NWS Hydro-21. US Department of Commerce, Washington, DC, $44 \mathrm{p}$

Ho FP, Tracey RJ (1975c) Storm tide frequency analysis for the coast of North Carolina, north of Cape Lookout. NOAA Technical Memo NWS Hydro-27. US Department of Commerce, Washington, DC, $46 \mathrm{p}$

Ho FP, Tracey RJ, Myers VA, Foat, NS (1976) Storm tide frequency analysis for the open coast of Virginia, Maryland, and Delaware. NOAA Technical Memo NWS Hydro-32. US Department of Commerce, Washington, DC, $52 \mathrm{p}$

Ho FP, Su JC, Hanevich KL, Smith RJ, Richards FP (1987) Hurricane climatology for the Atlantic and Gulf coasts of the United States. NOAA Technical Report NWS 38, Silver Spring, MD, 209 p

Holland GJ (1980) An analytic model of the wind and pressure profiles in hurricanes. Mon Wea Rev 108:1212-1218

Houston JR, Dean RG (2011) Sea-Level accelerations based on U.S. tide gauges and extensions of previous global gauge analyses. J Coastal Res 27(3):409-417

IPET (2009) Performance evaluation of the New Orleans and Southeast Louisiana Hurricane Protection System. Final Report of the Interagency Performance Evaluation Task Force, vol 8, Appendix 8, July U.S. Army Corps of Engineers

Irish JL, Resio DT (2010) A hydrodynamics-based surge scale for hurricanes. Ocean Eng 37:69-81

Irish J, Resio DT, Ratcliff J (2008) The influence of storm size on hurricane surge. J Phys Oceanog 38:2003-2103

Irish JL, Resio DT, Cialone MA (2009) A surge response function approach to coastal hazard assessment Part 2: quantification of spatial attributes of response functions. Nat Haz 51(1):183-205. doi: 10.1007/s11069-009-9381-4 
Jelesnianski CP, Chen J, Shaffer WA (1992) SLOSH: sea, lake, and overland surges from hurricanes. NOAA technical report NWS 48, National ocean and atmospheric administration, national weather service, Silver Springs, MD, $65 \mathrm{p}$

Katz RW, Brown BG (1992) Extreme events in a changing climate: variability is more important than averages. Clim Change 21:289-302

Kleinosky L, Yanral B, Fisher A (2007) Vulnerability of Hampton Roads, Virginia to storm surge flooding and sea-level rise. Nat Haz 40(1):43-70

Knaff JA, Zehr RM (2007) Reexamination of tropical cyclone wind-pressure relationships. Wea For 22:71-88

Knapp KR, Kruk MC, Levinson DH, Diamond HJ, Neumann CJ (2010) The international best track archive for climate stewardship (IBTrACS): unifying tropical cyclone best track data. Bull Am Meteor Soc 91:363-376

Knutson TR, Sirutis JJ, Garner ST, Held IM, Tuleya RE (2007) Simulation of the recent multidecadal increase of Atlantic hurricane activity using an 18-km-grid regional model. Bull Am Meteorol Soc 88(10): $1549-1566$

Knutson T, McBride J, Chan J, Emanuel K, Holland G, Landsea C, Held I, Kossin J, Srivastava A, Sugi M (2010) Tropical cyclones and climate change. Nat Geosci 3:157-163

Ko DS, Preller R, Martin P (2003) An experimental real-time Intra-Americas Sea Ocean Nowcast/Forecast System for coastal ocean prediction. In: Proceedings of the 5th AMS conference on coastal atmospheric and oceanic prediction and processes, AMS, Seatttle, WA, pp 97-100

Ko DS, Martin PJ, Rowley CD, Preller RH (2008) A real-time coastal ocean prediction experiment for MREA04. J Marine Syst 69:1728

Kotz S, Nadarajah S (2000) Extreme value distributions: theory and applications. Imperial College Press, London

Landsea CW (2005) Hurricanes and global warming. Nature 438:E11-E13

Lin N, Emanuel KA, Smith JA, Vanmarcke E (2010) Risk assessment of hurricane storm surge for New York City. J Geophys Res 115:D18121. doi:10.1029/2009JD013630

Luettich R, Westerink JJ, Scheffner NW (1992) ADCIRC: an advanced three-dimensional circulation model for shelves coasts and estuaries, report 1: theory and methodology of ADCIRC-2DDI and ADCIRC3DL. Dredging research program technical report DRP-92-6, U.S. Army Engineers Waterways Experiment Station, Vicksburg, MS, p 137

Meehl GA et al (2007) Global climate projections climate change 2007. The physical science basis. Contribution of working group I to the 4th assessment report of the intergovernmental panel on climate change. Cambridge University Press, Cambridge, United Kingdom, and New York, NY, USA

Mousavi ME, Irish JL, Frey AE, Olivera F, Edge BL (2011) Global warming and hurricanes: the potential impact on hurricane intensification and sea level rise on coastal flooding. Clim Change 104:575-597

Murty TS (1984) Storm surges: meteorological ocean tides. Canadian Bulletins of Fisheries and Aquatic Sciences, Ottawa

Myers VA (1970) Joint probability method of tide frequency analyses applied to Atlantic City and Long Beach Island, NJ. ESSA technical memo WBTM Hydro-11. US Department of Commerce, Washington, DC

Myers VA (1975) Storm tide frequencies of the South Carolina coast. NOAA technical report NWS-16. US Department of Commerce, Silver Springs, MD, $87 \mathrm{p}$

National Hurricane Center (2010a) Storm surge maximum of maximum (MOM). NOAA/National Weather Service http://www.nhc.noaa.gov/ssurge/ssurge_momOverview.shtml. Accessed 17 Jan 2011

National Hurricane Center (2010b) The Saffir-Simpson hurricane wind scale. NOAA/National Weather Service http://www.nhc.noaa.gov/aboutsshws.shtml. Accessed 14 Jan 2011

Niedoroda AW, Resio DT, Toro GR, Divoky D, Das HS, Reed CW (2010) Analysis of the coastal Mississippi storm surge hazard. Ocean Eng 37:82-90

NOAA Coastal Services Center (2010) Digital coast: coastal lidar http://www.csc.noaa.gov/digital coast/data/coastallidar/index.html. Accessed on 20 Aug 2010

NOAA National Geophysical Data Center (2010) Marine geophysical data access http://www.ngdc.noaa. gov/mgg/geodas/geodas.html. Accessed on 20 Aug 2010

NOAA Tides and Currents (2010) Sea levels online. http://tidesandcurrents.noaa.gov/sltrends/sltrends.shtml. Accessed on 3 Oct 2010

NRC (2009) Mapping the zone-improving flood map accuracy. National research council of the national academies, Committee on FEMA flood maps, National Academies Press. Washington, DC, $136 \mathrm{p}$

NRC (2010) Climate stabilization targets: emissions, concentrations, and impacts over decades to millennia. National Research Council of the National Academies, National Academies Press, Washington, DC, $232 \mathrm{p}$ 
Oey LY, Wang DP, Fan SJ, Yin XQ (2006) Loop current warming by Hurricane Wilma. Geophys Res Lett 33(L08613). doi:10.1029/2006GL025873

Paramygin VA, Sheng YP (2011) Simulating the unusual storm surge and coastal inundation in SW Florida during Hurricane Wilma in 2005, Submitted to J Geophys Res

Peng M, Xie L, Pietrafesa LJ (2004) A numerical study of storm surge and inundation in the CroatanAlbemarle-Pamlico estuary system. Est Coast Shelf Sci 59:121-137

Rahmstorf S (2010) A new view on sea level rise. Nat Reps Clim Change 4:44-45

Rego JL, Li C (2009) On the importance of the forward speed of hurricanes in storm surge forecasting: a numerical study. Geophys Res Let 36(L07609). doi:10.1029/2008GL036953

Resio DT (2007) White paper on estimating hurricane inundation probabilities, US Army Corps of Engineers Engineer Research and Development Center, Vicksburg, MS, $126 \mathrm{p}$

Ris RC, Booij N, Holthuijsen LH (1999) A third-generation wave model for coastal regions, part II, verification. J Geophys Res 104(C4):7667-7681

Shen W (2006) Does the size of hurricane eye matter with its intensity? Geophys Res Let 33:L18813, 4 p

Sheng YP (1987) On modeling three-dimensional estuarine and marine hydrodynamics. In: Nihoul JCJ, Jamart BM (eds) Three-dimensional models of marine and estuarine dynamics. Elsevier Science Publishing Company INC., New York, pp 35-54

Sheng YP (1990) Evolution of a three-dimensional curvilinear-grid hydrodynamic model for estuaries, lakes and coastal waters: $\mathrm{CH} 3 \mathrm{D}$, estuarine and coastal modeling. In: Proceedings of the estuarine and coastal circulation and pollutant transport model data comparison specialty conference, ASCE, Reston, VA, pp 40-49

Sheng YP, Kim T (2009) Skill assessment of an integrated modeling system for shallow coastal and estuarine ecosystems. J Mar Sys 76(1-2):212-243

Sheng YP, Paramygin VA (2010) Forecasting storm surge, inundation, and 3D circulation along the Florida coast, estuarine and coastal modeling. In: Proceedings of the 11th international conference, ASCE, Reston, VA, pp 744-761

Sheng YP, Villaret C (1989) Modeling the effect of suspended sediment stratification on bottom exchange process. J Geophys Res 94(C10):14229-14444

Sheng YP, Paramygin VA, Alymov V, Davis JR (2006) A real-time forecasting system for hurricane induced storm surge and coastal flooding, estuarine and coastal modeling. In: Proceedings of the 9th international conference, ASCE, Reston, VA, pp 585-602

Sheng YP, Alymov V, Paramygin VA (2010a) Simulation of storm surge, wave, currents, and inundation in the outer banks and chesapeake bay during hurricane isabel in 2003: the importance of waves. J Geophys Res Oceans 115(C04008):1-27

Sheng YP, Zhang Y, Paramygin VA (2010b) Simulation of storm surge, wave, and coastal inundation in the Northeastern Gulf of Mexico region during Hurricane Ivan in 2004. Ocean Mod 35:314-331

Sheng YP, Davis JR, Paramygin VA, Xie L, Liu H, Luettich R, Weaver RA, Weisberg R, Zheng L (2011) A regional testbed of storm surge and coastal inundation models, ongoing work funded by the NOAA IOOS program

Smolyak SA (1963) Quadrature and interpolation formulas for tensor products of certain classes of functions. Soviet Math Doklady 4:240-243

SWAN team (2009) Scientific and technical documentation SWAN cycle III version 40.72AB. http://vlm089.citg.tudelft.nl/swan/online_doc/swantech/swantech.html. Accessed 15 Dec 2010

Tolman HL (1999) User manual and system documentation of WAVEWATCH-III version 1.18. NOAA/ NWS/NCEP/OMB Technical Note 166, Washington, DC, $110 \mathrm{p}$

Tolman HL (2002) User manual and system documentation of WAVEWATCH-III version 2.22. NOAA/ NWS/NCEP/OMB technical note 222, Washington, DC, $133 \mathrm{p}$

Toro GR, Niedoroda AW, Reed C, Divoky D (2010a) Quadrature-based approach for the efficient evaluation of surge hazard. Ocean Eng 37:114-124

Toro GR, Resio DT, Divoky D, Niedoroda AW, Reed C (2010b) Efficient joint-probability methods for hurricane surge frequency analysis. Ocean Eng 37:125-134

United States Army Corps of Engineers (2006) Depth-damage relationships for structures, contents, and vehicles and content-to-structure value ratios (csvr) in support of the Donaldsonville to the Gulf Louisiana, feasibility study. Final Draft prepared by Gulf Engineers and Consultants, $163 \mathrm{p}$

United States Census (2011) 2010 US Census: apportionment data. US census bureau. http://2010.census. gov/2010census/data/index.php. Accessed 17 Jan 2011

United States Geological Survey (2010a) The national map: seamless data distribution viewer. http://seam less.usgs.gov/. Accessed 20 Aug 2010

United States Geological Survey (2010b) National land cover data set. http://seamless.usgs.gov/. Accessed 20 Aug 2010 
University of Florida, Bureau of Economic and Business Research (2005) Florida population studies, CC. Comprehensive Planning Department

University of Florida, Bureau of Economic and Business Research (2009) Florida city and county population report 2000-2009

Vecchi GA, Soden BJ (2007) Effect of remote sea surface temperature change on tropical cyclone potential intensity. Nature 450:1066-1070

Vermeer M, Rahmstorf S (2009) Global sea level linked to global temperature. Proc Natl Acad Sci USA $106: 21527-21532$

Vickery PJ (2005) Simple empirical models for estimating the increase in the central pressure of tropical cyclones after landfall along the coastline of the United States. J Appl Meteor 44:1807-1826

Wang C, Lee SK (2008) Global warming and United States landfalling hurricanes. Geophys Res Lett 35(L02708). doi:10.1029/2007GL032396

Weisberg RH, Zheng L (2008) Hurricane storm surge simulations comparing three-dimensional with two dimensional formulations based on an Ivan-like storm over the Tampa Bay, Florida region. J Geophys Res 113(C12001). doi:10.1029/2008JC005115

Wu SY, Yarnal B, Fisher A (2002) Vulnerability of coastal communities to sea-level rise: a case study of Cape May County, New Jersey. Climate Res 22:255-270

Yin J, Griffies SM, Stouffer RJ (2010) Spatial variability of sea-level rise in 21st century projections. J Climate 23:4585-4607 